\title{
Average Fracture Energy for Crack Propagation in Postfire Concrete
}

\author{
Kequan Yu, Jiangtao Yu, and Zhoudao Lu \\ College of Civil Engineering, Tongji University, Shanghai 200092, China \\ Correspondence should be addressed to Jiangtao Yu; yujiangtao@tongji.edu.cn
}

Received 20 September 2013; Accepted 20 October 2013

Academic Editor: Filippo Berto

Copyright (C) 2013 Kequan Yu et al. This is an open access article distributed under the Creative Commons Attribution License, which permits unrestricted use, distribution, and reproduction in any medium, provided the original work is properly cited.

Wedge-splitting tests of postfire concrete specimens were carried out in the present research to obtain the load-displacement curves. Ten temperatures varying from room temperature to $600^{\circ} \mathrm{C}$ were employed. In order to calculate the accurate fracture energy, the tails of load-displacement curves were best fitted using exponential and power functions. Three fracture energy quantities (fracture energy $G_{\mathrm{F}}$, stable fracture energy $G_{\mathrm{FS}}$, and unstable fracture energy $G_{\mathrm{FU}}$ ) with their variation tendency and their mutual relationship were determined to predict energy consumption for the complete fracture propagation. Additionally, the stable fracture work $W_{\mathrm{FS}}$ was also calculated. All these fracture parameters sustain an increase-decrease tendency which means that the fracture property of postfire concrete shares the same tendency.

\section{Introduction}

Since the application of fracture mechanics to concrete, the energy consumption for crack propagation in concrete has been a popular topic. For concrete, the specific fracture energy $G_{\mathrm{F}}$ has been proven to be a useful parameter in the structure design and fracture behavior modeling. The specific fracture energy of concrete was defined based on a tensile test as the energy absorbed per unit crack area in widening the crack from zero to or beyond the critical value above which no stress can transmit [1]. Based on the work-of-fracture principle, three-point bending test [2], compact tension [3], and wedge-splitting method [4] were proposed as alternative methods to determine the specific fracture energy $G_{F}$. It is computed as the area under the entire imposed load $P$ and load-line displacement curve divided by the projected area of uncracked ligament, so the fracture energy $G_{\mathrm{F}}$ represents the average or nominal energy consumption of concrete for an entire crack propagation process.

The existence of fracture process zone FPZ ahead of a crack is now well accepted. Since the 1970s, it has been known that the evolution of the FPZ undergoes two distinct periods-precritical stable crack growth and unstable fracture process [5]. There is no doubt that crack propagation is accompanied by energy dissipation, and the motive for crack propagation comes from either work provided by the imposed load or released strain energy. Fracture energy is one appropriate consideration to describe the amount of energy consumed during crack propagation process.

It is worth noting that the fracture energy can only represent the amount of average energy dissipation for entire crack propagation from crack initiation to complete failure without characterizing crack stable propagation and unstable fracture periods. So even with $G_{\mathrm{F}}$, it is still not clear how much energy is dissipated during those two crack extension periods. Xu et al. [6] proposed two new concepts the stable fracture energy $G_{\mathrm{FS}}$ and unstable fracture energy $G_{\mathrm{FU}}$ to describe fracture responses for different crack propagation periods. It is found that $G_{\mathrm{FS}}$ kept constant for different ligament lengths, whereas $G_{\mathrm{F}}$ and $G_{\mathrm{FU}}$ showed the apparent size effect. But the accurate calculation of fracture surface remains unsolved. It is known that the true path of crack extension is tortuous, not straight as expected. The projected area underestimates the true fracture area. Hence, these parameters are actually nominal values.

The fracture energy of postfire concrete has been studied by several researchers [7-12]. It is found that the residual fracture energy sustained an increase-decrease tendency with the turning point at approximately $450^{\circ} \mathrm{C}$. The increase tendency is due to the energy dissipation of microcracks distributing in 
the concrete, whereas the thermal damage induced by high temperatures reduces the residual fracture energy. However, in these researches, the influence of loading-displacement tail was unknown or not considered.

In present paper, wedge-splitting experiments of under ten temperatures levels varying from $20^{\circ} \mathrm{C}$ to $600^{\circ} \mathrm{C}$ and the specimens size of $230 \mathrm{~mm} \times 200 \mathrm{~mm} \times 200 \mathrm{~mm}$ with initialnotch depth ratios 0.4 are implemented [12]. Based on the work-of-fracture idea, the residual fracture energy $G_{\mathrm{F}}$ is calculated considering the influence of load-displacement tail. Furthermore, the fracture energy consumption for crack stable extension and unstable extension, that is, $G_{\mathrm{FS}}, G_{\mathrm{FU}}$, is investigated. However, the true fracture surface remains undetermined and extremely difficult for specimens subjected to high temperatures, so these three fracture energy parameters are still nominal values. Hence, corresponding to $G_{\mathrm{FS}}$ and $G_{\mathrm{FU}}$, the stable and unstable fracture work which neglect the fracture surface and their variation about temperatures are thus determined. From these parameters the fracture properties of postfire concrete could be described.

\section{Fracture Energies for an Entire Crack Propagation Period}

Based on the global energy balance principle, the work performed by a generalized force $P$ on its displacement will be transformed into energy: one part of energy is stored in the body in the form of strain energy and the other part is used for crack propagation. It can be mathematically written as [6]:

$$
G_{\mathrm{Fi}} A_{i}=W_{i}-\Delta U_{i}=\int_{0}^{\delta_{i}} P d \delta-\Delta U_{i}
$$

where $G_{F i}=$ average energy needed for unit crack propagation during period from crack initiation to any instant of time $i$; $A_{i}=$ newly formed fracture area for this period; the product of these two quantities represents the energy absorbed for crack propagation during this period; $W_{i}=$ work performed by the external force $P$ during the same period; $U_{i}=$ increase of elastic strain energy of the body until time $i ; \delta_{i}=$ crack opening displacement corresponding to $P$. If time $i$ is approaching the failure terminal point $i=1$, where the load drops to zero, then $G_{F i}$ in (1) will reduce to

$$
G_{\mathrm{F}}=\frac{W}{A_{\text {lig }}}=\frac{\int_{0}^{\delta_{1}} P d \delta}{b\left(h-a_{0}\right)},
$$

where $G_{\mathrm{F}}=$ RILEM fracture energy; $W=$ total energy provided by the external force $P$ for crack propagation; $A_{\text {lig }}=$ projected fracture area perpendicular to the tensile stress direction; $b=$ specimen thickness; $h=$ specimen height; $a_{0}=$ initial crack length.

During the stable crack propagation period, the load will increase up to its peak value $P_{\max }$ with its corresponding displacement reaching $\mathrm{COD}_{c}$; see Figure 1. So, based

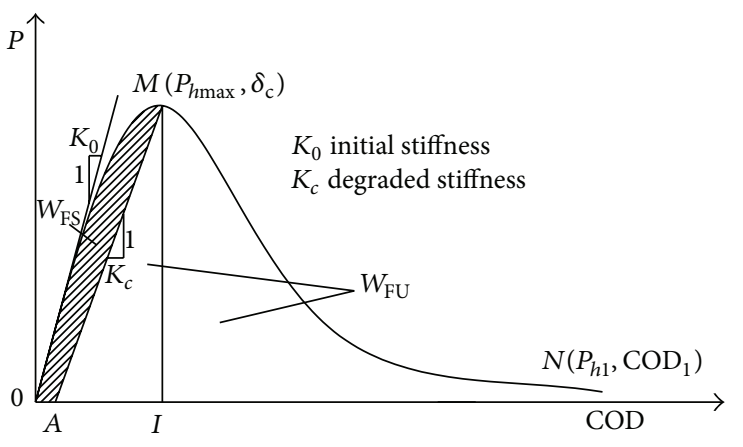

FIGURE 1: Energy consumption for an entire crack propagation period.

on (1), the average energy absorbed during this period can be evaluated by

$$
\begin{aligned}
G_{\mathrm{FS}} & =\frac{W_{\mathrm{FS}}}{A_{\mathrm{S}}}=\frac{W_{P}-\Delta U_{\mathrm{S}}}{A_{\mathrm{S}}}=\frac{W_{\mathrm{OAMO}}}{A_{\mathrm{S}}} \\
& =\frac{W_{\mathrm{OIMO}}-W_{\mathrm{AIMA}}}{A_{\mathrm{S}}}=\frac{\int_{0}^{\mathrm{COD}_{c}} P d \mathrm{COD}_{c}-\Delta U_{\mathrm{S}}}{A_{\mathrm{S}}}
\end{aligned}
$$

where $G_{\mathrm{FS}}$ by naming the stable fracture energy = average energy needed for the crack to grow unit area during the crack stable propagation; $A_{\mathrm{S}}=$ change in fracture area; $W_{\mathrm{FS}}=$ $W_{\text {OAMO }}=$ energy provided for stable crack propagation as shown in Figure 1 by the shaded area; $W_{P}=W_{\text {OIMO }}=$ work performed by the external force $P$ for crack increases its area $A_{S} ; \Delta U_{\mathrm{S}}=W_{\mathrm{AIMA}}=$ increased elastic strain energy of the body; and $\mathrm{COD}_{c}=$ critical crack opening displacement.

From the definition of the stable fracture energy $G_{\mathrm{FS}}$, it is implied that the work from the imposed load $P$ is expended in two forms during the crack stable propagation: one part is stored in the body in the form of the elastic strain energy $\left(\Delta U_{S}\right)$ and the other part is the energy absorbed by the fracture zone mainly to counteract the resistance caused by the cohesive forces along the FPZ. In the same way, the unstable fracture energy, denoted by $G_{\mathrm{FU}}$, is defined based on energy equilibrium as

$$
G_{\mathrm{FU}}=\frac{W_{\mathrm{U}}}{A_{\mathrm{U}}}=\frac{W-W_{\mathrm{S}}}{A_{\mathrm{U}}},
$$

where $W_{\mathrm{U}}=$ energy needed for the crack unstable propagation period and $A_{\mathrm{U}}=$ change in fracture area. During this period, the stored energy is completely released until the deformation reaches its maximum value $\mathrm{COD}_{1}$ when the load closes to zero. Similar to the RILEM fracture energy $G_{\mathrm{F}}$, the establishment of the stable fracture energy $G_{\mathrm{FS}}$ and unstable fracture energy $G_{\mathrm{FU}}$ rests upon the implicit assumption that no other energy consumption occurs outside the fracture zone. 

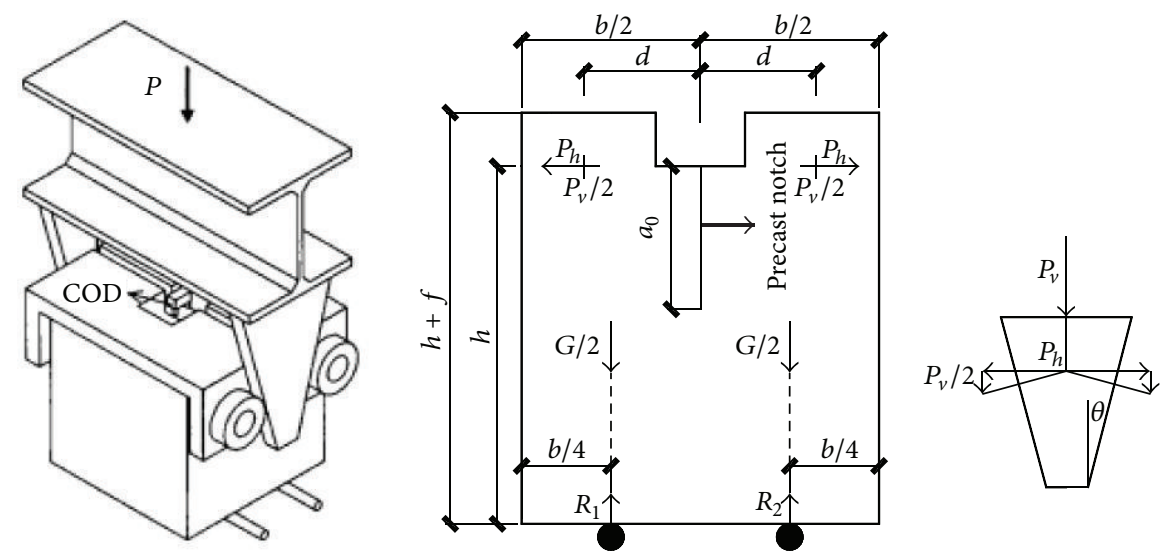

FIGURE 2: Test setup and geometry of specimens.

\section{Experimental Program and Experimental Phenomena}

In this test, concrete specimens were prepared using an ordinary silicate cement PO. 42.5 produced conforming to the Chinese standard. Coarse aggregate was calcareous crushed stone with a maximum size of $16 \mathrm{~mm}$, and river sand was used as the fine aggregates and its maximum diameter was $5 \mathrm{~mm}$. Details of the mix proportioning (by weight) used for concrete and some mechanical properties are Cement: Sand:Limestone Coarse aggregate: Water:fly ash $=1.00: 3.44: 4.39: 0.80: 0.26$.

Fracture properties of concrete were determined by means of the wedge splitting test [4]. The test setup and geometry of the specimen are schematically represented in Figure 2. Compared to three-point bending notched beams, the wedge-splitting test has following advantages. For the three-point bending beams, inaccurate measurement of loadpoint displacement and the self-weight of the specimen could influence the real value of the fracture energy. During the test, beams should be carefully handled due to their heavy weight. However, using the WS specimens, the recorded COD in a horizontal plane is not affected by the crushing of the specimen at the supports or some other factors. Besides, the WS specimens are simple and easily prepared in laboratories or on site.

A total of 50 concrete specimens with the same dimensions $230 \times 200 \times 200 \mathrm{~mm}$ were prepared; the geometry of the specimens and the test setup are shown in Figure $2(b=$ $200 \mathrm{~mm}, d=65 \mathrm{~mm}, h=200 \mathrm{~mm}, f=30 \mathrm{~mm}, a_{0}=$ $80 \mathrm{~mm}$, and $\theta=15^{\circ}$ ). All the specimens had a precast notch of $80 \mathrm{~mm}$ height and $3 \mathrm{~mm}$ thickness, achieved by placing a piece of steel plate into the molds prior to casting. Each wedge splitting specimen was embedded with a thermal couple in the center of specimen for temperature control.

Nine heating temperatures, ranging from $65^{\circ} \mathrm{C}$ to $600^{\circ} \mathrm{C}$ $\left(T_{m}=65^{\circ} \mathrm{C}, 120^{\circ} \mathrm{C}, 200^{\circ} \mathrm{C}, 300^{\circ} \mathrm{C}, 350^{\circ} \mathrm{C}, 400^{\circ} \mathrm{C}, 450^{\circ} \mathrm{C}\right.$, $500^{\circ} \mathrm{C}$, and $600^{\circ} \mathrm{C}$ ), were adopted with the ambient temperature as a reference. Because it was recognized that the fracture behavior measurements were generally associated with significant scatter, five repetitions were performed for each temperature.

An electric furnace with net dimensions $300 \times 300 \times$ $900 \mathrm{~mm}$ was used for heating. When the designated $T_{m}$ was reached, the furnace was shut down, and the specimens were naturally cooled for 7 days prior to the test. It averagely took 50, 95, 135, 182, 218, 254, 294, 342, and 453 minutes for the specimens to reach the final temperatures, respectively (from $65^{\circ} \mathrm{C}$ to $600^{\circ} \mathrm{C}$ ). Figure 3 shows the typical temperature history for several cases with different maximum temperatures. After heating, microcracks disperse on the specimen surface, especially for temperatures higher than $200^{\circ} \mathrm{C}$ (see in Figure 4).

The fracture surfaces at different temperature intervals $\left(20^{\circ} \mathrm{C}, 200^{\circ} \mathrm{C}, 350^{\circ} \mathrm{C}, 450^{\circ} \mathrm{C}\right.$, and $\left.600^{\circ} \mathrm{C}\right)$ are shown in Figure 5, which became lighter but more tortuous with increasing temperatures.

A universal machine with a maximum capacity of $1000 \mathrm{kN}$ was used to conduct the wedge splitting tests. During the test, the vertically applied load $P_{v}$ and the crack opening displacement COD along the horizontal load line were simultaneously recorded through a data acquisition system. Referring to Figure 2, the splitting force $P_{h}$ is actually the horizontal component of the force acting on the bearing. Taking the wedge angle into consideration, its relation with the recorded applied load $P_{v}$ can be developed based on force equilibrium ignoring the small influence from the friction for different roller bearings:

$$
P_{h}=\frac{P_{v}}{2 \tan \theta}
$$

To obtain the complete $P$-COD curves (shown in Figure 6), the test rate was fixed at $0.4 \mathrm{~mm} / \mathrm{min}$, such that it took approximately 20 minutes to complete a single test of specimens subjected to less than $300^{\circ} \mathrm{C}$ and 30 minutes for beyond $300^{\circ} \mathrm{C}$.

The fracture of specimen is essentially due to the bending moment caused by the horizontal splitting force $P_{h}$, vertical component $1 / 2 P_{v}$, and self-weight of the specimen. Two 


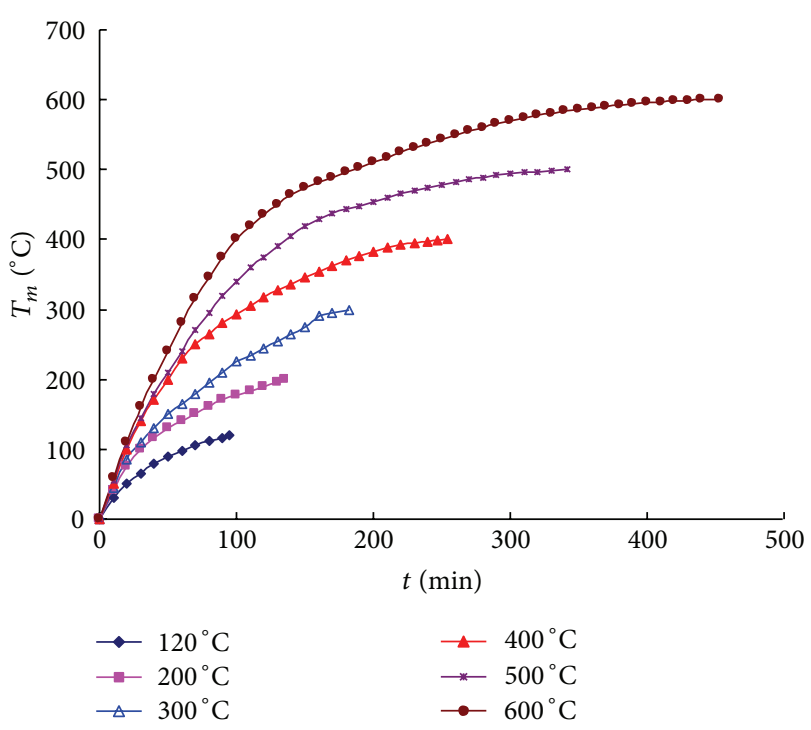

FIGURE 3: Typical temperature history of specimens.

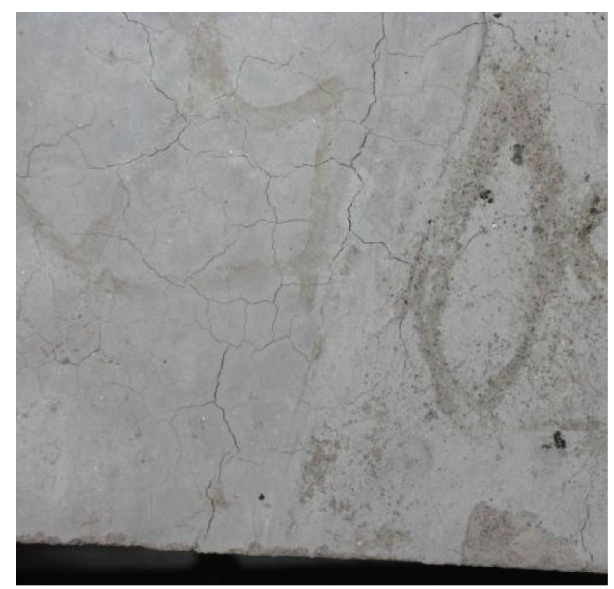

FIGURE 4: Microcracks on specimen surface $\left(600^{\circ} \mathrm{C}\right)$.

symmetrical supports are placed below the center of gravity of each half of the specimen. In doing so, the influence of the dead weight of the specimen and part of the vertical component force on the calculation of the fracture energies could be counteracted. Each roll axis is fixed at the same horizon as the lower plane of the groove and is very close to the center of gravity of each half of the specimen in the vertical position (shown in Figure 2). Due to the carefulness in the choice of the specimen geometry, the roll axis location, and the placement of the supports, the horizontal force $P_{h}$ contributes most to fracturing the specimen. Therefore, $P_{h^{-}}$ COD curves were directly used in the calculation of the RILEM fracture energy $G_{\mathrm{F}}$, stable fracture energy $G_{\mathrm{FS}}$, and unstable fracture energy $G_{\mathrm{FU}}$.

For our test results, the $P_{h}$-COD curves could be easily obtained from the monitored $P_{v}$-COD curves and (5). Figure 6 contains the plots of $P_{h}$-COD curves for several temperatures and typical $P_{v}$-COD curves for all temperatures.
From Figure 6(a) to 6(c), it is found that with the increasing of temperature $\left(20^{\circ} \mathrm{C}-600^{\circ} \mathrm{C}\right)$, the divergence between the curves for the same temperature is more significant. In particular $600^{\circ} \mathrm{C}$, the ultimate load $P_{u}$ of specimen WS50 is one time higher than the one of specimen WS47. Additionally, the whole loading process is not stable for specimens WS49 (a sudden snap-back) due to the thermal damage induced by high temperature. Figure 6(d) shows the typical $P$-COD curves of all temperatures. The ultimate load $P_{u}$ decreases significantly with increasing temperatures $T_{m}$, whereas the crack mouth opening displacement (COD) increases with $T_{m}$. The initial slope of ascending branches decreases with heating temperatures, and the curves become gradually shorter and more extended.

It is found that the ultimate load $P_{h \text { max }}$ decreases with the increasing temperatures, whereas the $\mathrm{COD}_{c}$ increases with $T_{m}$ (Figure 8). The average value of $P_{u}$ decreases from $9.17 \mathrm{kN}$ at ambient temperature to $7.92 \mathrm{kN}$ at $120^{\circ} \mathrm{C}, 4.29 \mathrm{kN}$ at $300^{\circ} \mathrm{C}$, $3.16 \mathrm{kN}$ at $450^{\circ} \mathrm{C}$, and finally $1.38 \mathrm{kN}$ at $600^{\circ} \mathrm{C}$, with a final drop of $85 \%$. The value of $\mathrm{COD}_{c}$ increases from $0.178 \mathrm{~mm}$ at ambient temperature to $0.352 \mathrm{~mm}$ at $200^{\circ} \mathrm{C}, 0.901 \mathrm{~mm}$ at $400^{\circ} \mathrm{C}$, and $1.848 \mathrm{~mm}$ at $600^{\circ} \mathrm{C}$, nearly 10 times as the ambient value.

\section{Experimental Results and Analysis}

4.1. Determination of Residual Fracture Energy $G_{F}$. In the calculation of RILEM fracture energy $G_{F}$, two things should be carefully considered. One thing is that the work done by the self-weight of loading device should be taken into account. In present experiments, the loading device is attached to the testing machine and the $P_{h}$-COD curve includes the selfweight; hence the work should not be calculated again. The other concern pertains to the tail part of the $P_{h}$-COD curve: the recorded point $\left(P_{h 1}, \mathrm{COD}_{1}\right)$ is just one point when the experiment stops, not the actual point of when the load drops to zero. Therefore, cutting the load-deflection tail may lead to noticeable inaccuracy in the true value of fracture energy. Thus, to account for these two factors, the actual RILEM fracture energy $G_{F}$ based on the work-of-fracture method becomes (see Figure 9)

$$
G_{\mathrm{F}}=\frac{W}{A_{\operatorname{lig}}}=\frac{W_{1}+W_{2}}{t\left(h-a_{0}\right)},
$$

where $W_{1}=$ measured work enclosed by the $P_{h}$-COD curve until $\mathrm{COD}=\mathrm{COD}_{1} ; A_{\text {lig }}=$ fresh fracture area; $W_{2}$ is the work caused by tail effect part. For $W_{2}$, curve fitting technology based on Excel software was used to get its approximate value. In previous research from the test results at ambient temperature [13], it was found out that the descending branch of the $P_{h}$-COD curve after one-third of the peak load could be well described by power function (the coefficient of determination $R^{2}$ for each curve is close to 1 ). This study indicates that for specimens subject to no more than $120^{\circ} \mathrm{C}$, the power function is more accurate; however, for specimens subject to higher temperatures, exponential function is more suitable (see Figure 9). 


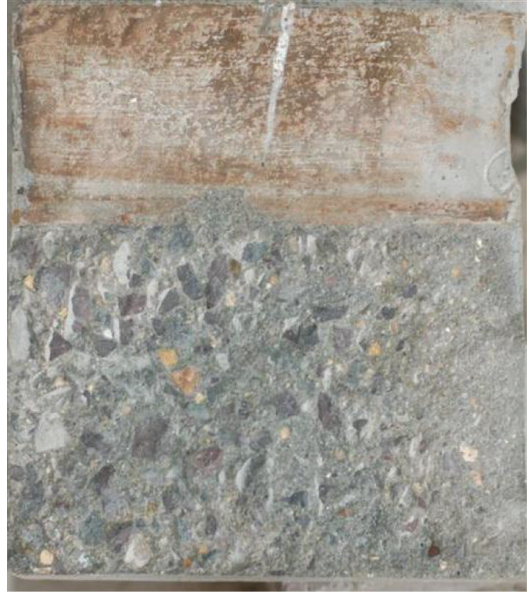

(a) Fracture surface of $20^{\circ} \mathrm{C}$

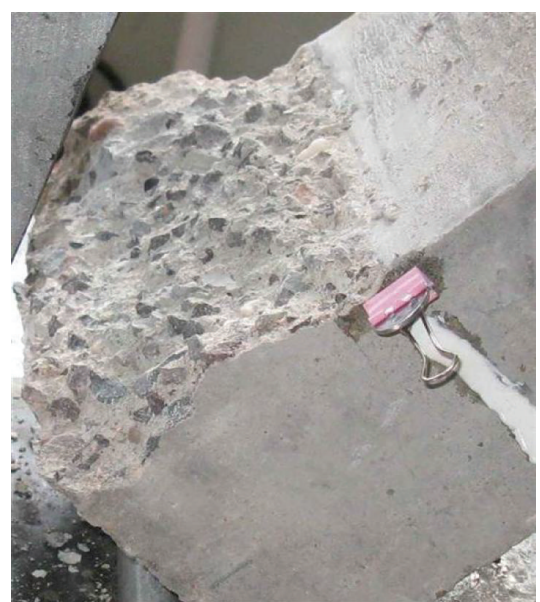

(b) Fracture surface of $600^{\circ} \mathrm{C}$

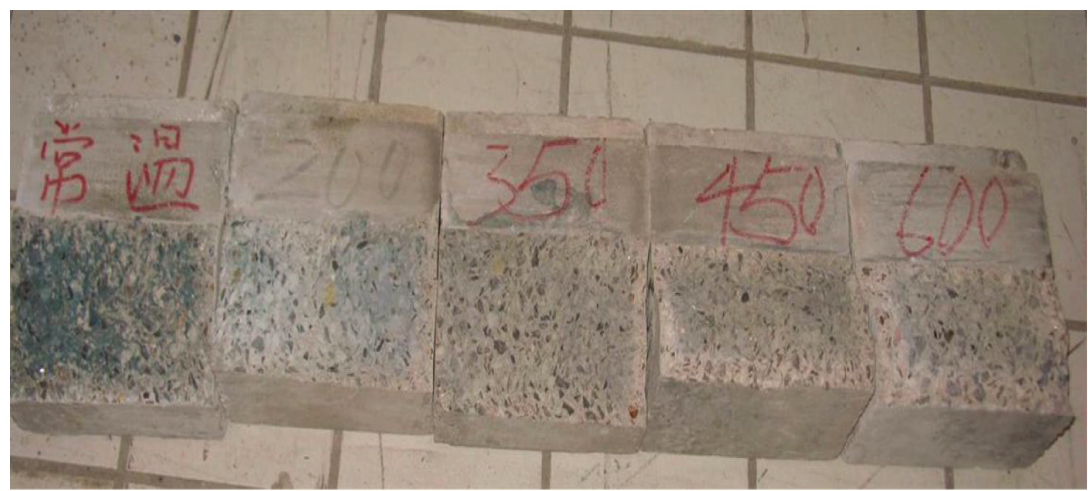

(c) Fracture surfaces at typical temperatures $\left(20^{\circ} \mathrm{C}, 200^{\circ} \mathrm{C}, 350^{\circ} \mathrm{C}, 450^{\circ} \mathrm{C}\right.$, and $\left.600^{\circ} \mathrm{C}\right)$

FIGURE 5: Fracture surfaces of postfire specimens.

For power function $P_{h}=\beta \times \operatorname{COD}^{-\lambda} \beta, \lambda>0$, where $\beta, \lambda=$ constants for fitting curves. And then the unrecorded work $W$ owning to cutting load-deflection tail can be written as

$$
W_{2}=\int_{\mathrm{COD}_{1}}^{\infty} \beta \times \mathrm{COD}^{-\lambda} d \mathrm{COD}=\frac{\beta}{(\lambda-1) \times \mathrm{COD}_{1}^{\lambda-1}}
$$

For exponential function $P_{h}=m \times e^{-n \times \mathrm{COD}} m, n>0$, where $m, n=$ constants for fitting curves. And then the unrecorded work $W$ owning to cutting load-deflection tail can be written as

$$
W_{2}=\int_{\mathrm{COD}_{1}}^{\infty} m \times e^{-n \times \mathrm{COD}} d \delta=\frac{m}{n e^{n \times \mathrm{COD}_{1}}} .
$$

The parameters of $\beta, \lambda$ for $20^{\circ} \mathrm{C} \sim 120^{\circ} \mathrm{C}$ and $m, n$ for $200^{\circ} \mathrm{C} \sim 600^{\circ} \mathrm{C}$, and the value of $w_{1}, w_{2}$ is listed in Table 1.

Some necessary test results are tabulated in Table 1 , including the maximum value of the horizontal load $P_{h \max }$ and its corresponding crack opening displacement $\mathrm{COD}_{c}$, the endpoint where $P_{h 1}$ approaches zero and the crack opening displacement arrives at $\mathrm{COD}_{1}$, the initial slope of $P_{h}$-COD, that is, the initial stiffness $K_{0}$, and the modulus of elasticity $E$.

Hence, the residual fracture energy described by (1) could be calculated. The values are listed in Table 2 and are shown in Figure 10.

Though the residual fracture energy at each temperature has significant scatter, Figure 10 shows that the average values sustain an increase-decrease tendency with $T_{m}$. From $20^{\circ} \mathrm{C}$ to $450^{\circ} \mathrm{C}$, average $G_{\mathrm{F}}$ increases from $339.3 \mathrm{Nm}^{-1}$ to $609 \mathrm{Nm}^{-1}$, while the temperature reaches $600^{\circ} \mathrm{C}$ and the fracture energy falls back to $307.8 \mathrm{Nm}^{-1}$. The detailed explanation would be seen elsewhere [12].

\subsection{Determination of Stable Fracture Energy $G_{F S}$ and Unstable} Fracture Energy $G_{F U}$. As an extension of fracture energy $G_{\mathrm{F}}$, two other energy-based fracture characteristics, the stable fracture energy $G_{\mathrm{FS}}$ and unstable fracture energy $G_{\mathrm{FU}}$, are proposed to describe fracture responses for different crack propagation periods. The analysis shows that fracture energy $G_{\mathrm{F}}$ is actually the weighed average of $G_{\mathrm{FS}}$ and $G_{\mathrm{FU}}$, and $G_{\mathrm{FS}}$ 


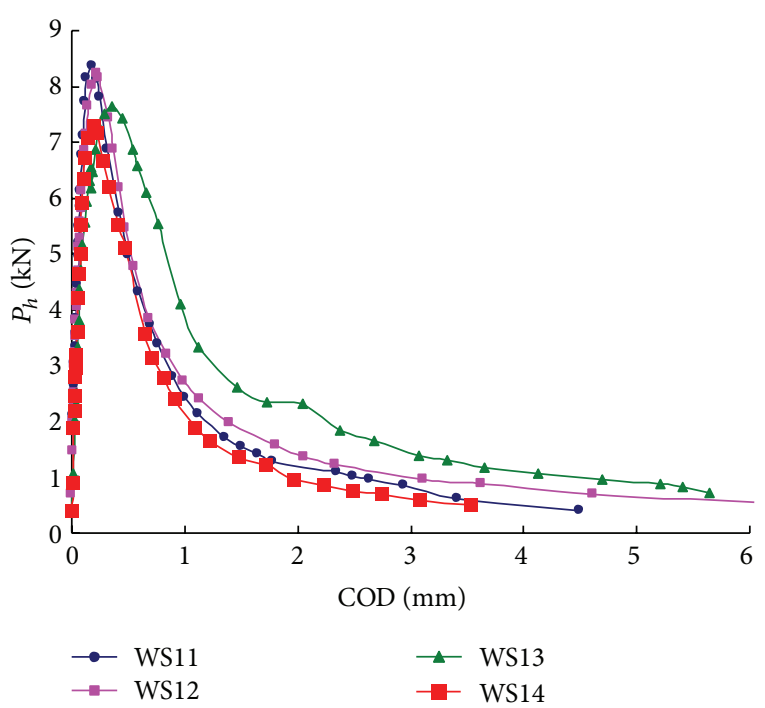

(a) $P_{h}$ versus COD curves of specimens at $120^{\circ} \mathrm{C}$

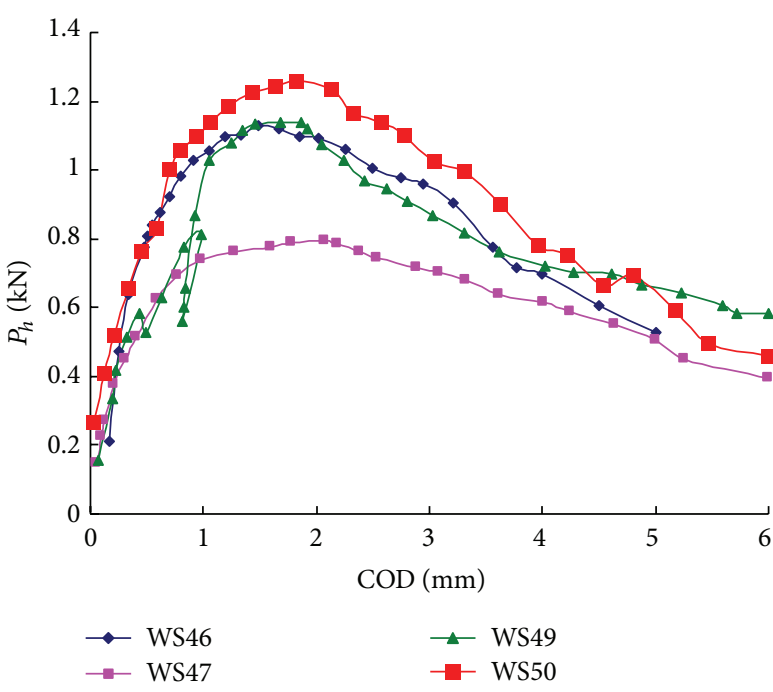

(c) $P_{h}$ versus COD curves of specimens at $600^{\circ} \mathrm{C}$

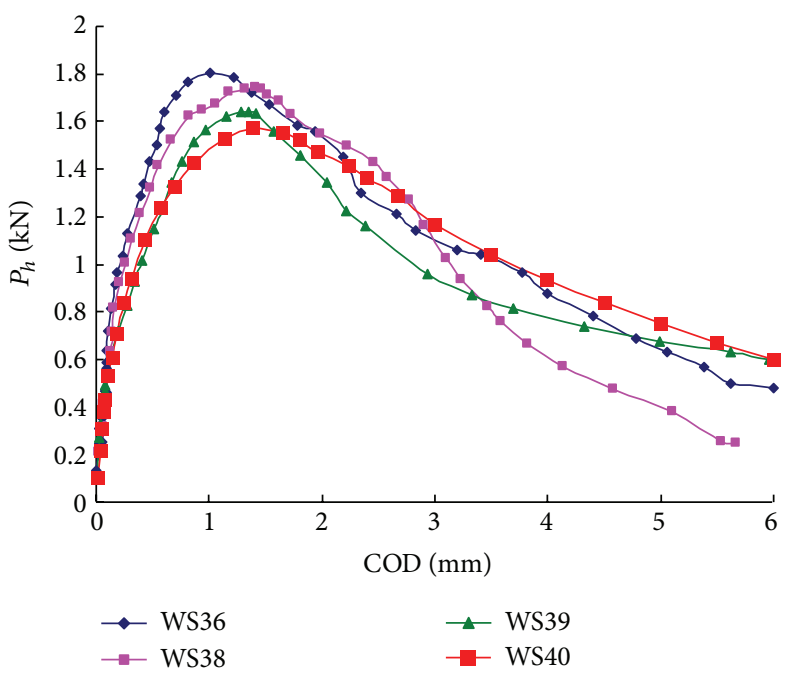

(b) $P_{h}$ versus COD curves of specimens at $450^{\circ} \mathrm{C}$

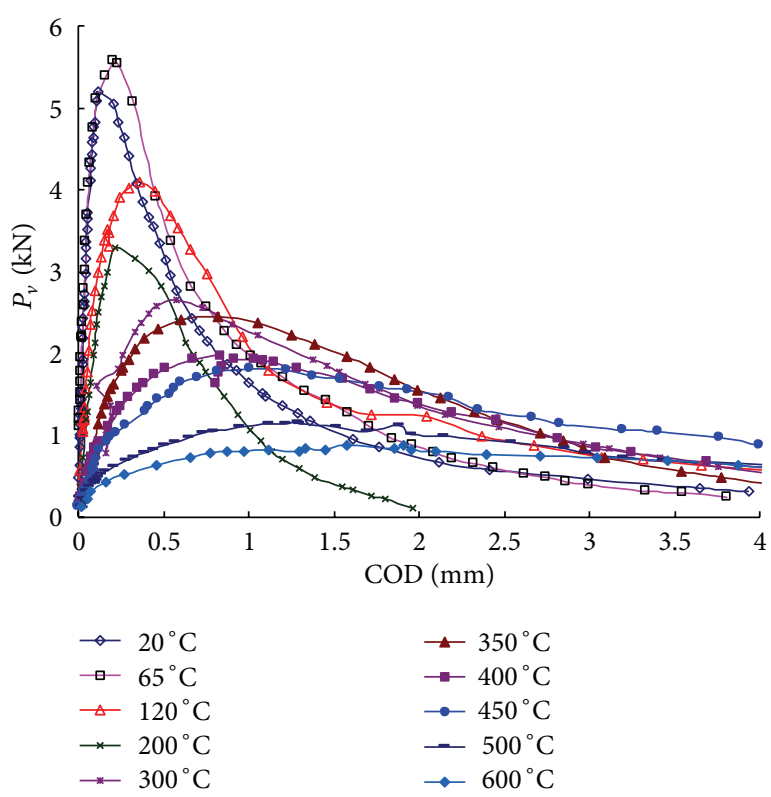

(d) Typical $P_{v}$ versus COD curves of specimens at all temperatures

Figure 6: $P$ versus CMOD curves of specimens with temperatures.

and $G_{\mathrm{FU}}$ could be regarded as two components of $G_{\mathrm{F}}$. This is very helpful in understanding the whole crack propagation process from the aspect of energy consumption.

To obtain the values of $G_{\mathrm{FS}}$ and $G_{\mathrm{FU}}$, the critical effective crack length $a_{c}$ should first be determined for the calculation of the fracture areas $A_{\mathrm{S}}$ and $A_{\mathrm{U}}$. Herein, the value $a_{c}$ was computed based on the double- $K$ fracture model [14]:

$$
a=\left(h+h_{0}\right)\left\{1-\left(\frac{13.18}{E \cdot b \cdot c+9.16}\right)^{1 / 2}\right\}-h_{0},
$$

where $c=\mathrm{COD} / P$ is the compliance of specimens, $E$ is modulus of elasticity, $b$ is specimen thickness, $h$ is specimen height, and $h_{0}$ is the thickness of the clip gauge holder. For calculation of critical value of equivalent elastic crack length $a_{c}$, the value of crack mouth opening displacement (COD) and $P$ are taken as $\mathrm{COD}_{c}$ and $P_{h \text { max }}$, respectively. Equation (9) is valid for $0.2-0.8$ within $2 \%$ accuracy. The value of $a_{c}$ is reported in Table 1.

In a typical load-displacement curve shown in Figure 1, $K_{0}$ is the initial stiffness of the load-displacement curve before the start of the fracture process. At critical state when the load arrives at its peak value $P_{\max }$ and its corresponding displacement reaches $\mathrm{COD}_{c}$, the stiffness $K_{c}$ may not be the same as the initial $K_{0}$. The degradation of stiffness is the result of crack propagation. To make it simple, here, the value 
TABle 1: Parameters calculated from wedge-splitting test.

\begin{tabular}{|c|c|c|c|c|c|c|c|c|c|c|c|c|c|}
\hline Specimen & Temperature & $\begin{array}{c}P_{h \max } \\
(\mathrm{kN})\end{array}$ & $E(\mathrm{GPa})$ & $a_{c}(\mathrm{~mm})$ & $\beta / m$ & $\lambda / n$ & $R^{2}$ & $W_{1}$ & $W_{2}$ & $\mathrm{COD}_{c}(\mathrm{~mm})$ & $\mathrm{COD}_{1}(\mathrm{~mm})$ & $\begin{array}{c}K_{0} \\
(\mathrm{kN} / \mathrm{mm})\end{array}$ & $\begin{array}{c}K_{c} \\
(\mathrm{kN} / \mathrm{mm})\end{array}$ \\
\hline WS1 & \multirow{5}{*}{$20^{\circ} \mathrm{C}$} & 8.304 & 15.30 & 0.107 & 1.484 & 2.273 & 0.970 & 5.231 & 0.389 & 0.174 & 1.926 & 87.081 & 79.219 \\
\hline WS2 & & 9.407 & 20.51 & 0.097 & 3.131 & 1.206 & 0.998 & 10.468 & 1.140 & 0.205 & 4.914 & 116.710 & 113.648 \\
\hline WS3 & & 10.379 & 20.66 & 0.114 & 2.464 & 1.117 & 0.991 & 8.699 & 1.818 & 0.195 & 3.280 & 117.610 & 110.633 \\
\hline WS4 & & 7.884 & 18.88 & 0.112 & 1.599 & 3.224 & 0.964 & 5.128 & 0.137 & 0.152 & 1.903 & 107.480 & 98.911 \\
\hline WS5 & & 9.364 & 15.45 & 0.107 & 2.048 & 1.683 & 0.991 & 6.970 & 0.735 & 0.199 & 2.657 & 87.940 & 80.103 \\
\hline Average & & 9.068 & 18.16 & 0.107 & - & - & 0.983 & 7.299 & 0.844 & 0.185 & 2.936 & 103.364 & 96.503 \\
\hline WS6 & \multirow{5}{*}{$65^{\circ} \mathrm{C}$} & 11.282 & 21.73 & 0.113 & 2.781 & 1.506 & 0.996 & 9.238 & 0.984 & 0.195 & 3.205 & 123.690 & 116.172 \\
\hline WS7 & & 8.151 & 24.79 & 0.132 & 2.739 & 0.987 & 0.999 & 10.320 & 1.263 & 0.215 & 6.072 & 141.100 & 136.109 \\
\hline WS8 & & 10.379 & 19.43 & 0.115 & 6.114 & 1.992 & 0.954 & 11.004 & 0.702 & 0.212 & 4.549 & 110.560 & 105.418 \\
\hline WS9 & & 10.681 & 23.25 & 0.119 & 2.658 & 1.030 & 0.993 & 9.283 & 2.250 & 0.164 & 3.535 & 132.330 & 124.685 \\
\hline WS10 & & 11.610 & 16.60 & 0.107 & 3.185 & 1.252 & 0.983 & 11.466 & 1.071 & 0.190 & 5.324 & 94.490 & 90.418 \\
\hline Average & & 10.421 & 21.16 & 0.117 & - & - & 0.985 & 10.262 & 1.254 & 0.195 & 4.537 & 120.434 & 114.560 \\
\hline WS11 & \multirow{5}{*}{$120^{\circ} \mathrm{C}$} & 8.353 & 10.65 & 0.095 & 2.477 & 1.085 & 0.990 & 8.423 & 1.094 & 0.191 & 3.418 & 60.638 & 57.254 \\
\hline WS12 & & 8.226 & 11.87 & 0.107 & 2.667 & 0.890 & 0.999 & 10.624 & 1.803 & 0.224 & 6.443 & 67.564 & 65.212 \\
\hline WS13 & & 7.631 & 9.48 & 0.119 & 4.340 & 0.998 & 0.980 & 13.227 & 2.487 & 0.357 & 5.641 & 53.926 & 50.511 \\
\hline WS14 & & 7.302 & 15.42 & 0.117 & 2.139 & 1.153 & 0.998 & 6.934 & 1.357 & 0.198 & 3.534 & 87.758 & 82.839 \\
\hline WS15 & & - & - & - & - & - & - & - & - & - & - & - & - \\
\hline Average & & 7.878 & 11.85 & 0.109 & - & - & 0.992 & 9.802 & 1.685 & 0.243 & 4.759 & 67.472 & 63.954 \\
\hline WS16 & \multirow{5}{*}{$200^{\circ} \mathrm{C}$} & - & - & - & - & - & - & - & - & - & - & - & - \\
\hline WS17 & & 6.466 & 11.58 & 0.127 & 2.266 & 1.526 & 0.952 & 6.260 & 0.520 & 0.284 & 2.558 & 65.913 & 57.759 \\
\hline WS18 & & 5.884 & 6.98 & 0.115 & 2.268 & 2.982 & 0.995 & 5.035 & 0.129 & 0.335 & 1.968 & 39.732 & 32.967 \\
\hline WS19 & & 5.071 & 9.17 & 0.127 & 2.770 & 2.087 & 0.969 & 5.397 & 0.265 & 0.306 & 2.786 & 52.178 & 46.456 \\
\hline WS20 & & 5.228 & 7.00 & 0.130 & 2.530 & 0.366 & 0.903 & 7.605 & 1.250 & 0.458 & 4.447 & 39.866 & 35.765 \\
\hline Average & & 5.662 & 8.68 & 0.125 & - & - & 0.955 & 6.074 & 0.541 & 0.346 & 2.940 & 49.422 & 43.237 \\
\hline WS21 & \multirow{5}{*}{$300^{\circ} \mathrm{C}$} & 3.341 & 2.45 & 0.121 & 4.023 & 0.361 & 0.981 & 10.019 & 0.491 & 0.792 & 3.101 & 13.939 & 11.004 \\
\hline WS22 & & 5.513 & 3.49 & 0.117 & 4.090 & 0.300 & 0.987 & 13.570 & 1.105 & 0.667 & 5.065 & 19.869 & 17.251 \\
\hline WS23 & & 3.371 & 1.91 & 0.113 & 6.985 & 0.610 & 0.982 & 7.727 & 0.475 & 0.672 & 4.957 & 10.854 & 9.384 \\
\hline WS24 & & 4.761 & 1.99 & 0.105 & 4.285 & 0.345 & 0.990 & 12.552 & 0.987 & 0.728 & 6.816 & 11.350 & 10.138 \\
\hline WS25 & & 4.076 & 4.03 & 0.137 & 2.172 & 0.206 & 0.963 & 11.532 & 1.667 & 0.869 & 6.874 & 22.960 & 20.438 \\
\hline Average & & 4.213 & 2.78 & 0.119 & - & - & 0.981 & 11.080 & 0.945 & 0.746 & 5.363 & 15.794 & 13.643 \\
\hline WS26 & \multirow{5}{*}{$350^{\circ} \mathrm{C}$} & 5.701 & 6.05 & 0.131 & 5.702 & 0.447 & 0.995 & 12.290 & 1.475 & 0.599 & 4.549 & 34.409 & 29.878 \\
\hline WS27 & & 3.840 & 2.03 & 0.125 & 6.245 & 0.335 & 0.958 & 14.150 & 1.490 & 1.003 & 6.768 & 11.538 & 9.829 \\
\hline WS28 & & 4.718 & 3.60 & 0.131 & 5.553 & 0.454 & 0.997 & 11.312 & 1.107 & 0.815 & 4.053 & 13.490 & 16.360 \\
\hline WS29 & & 4.554 & 3.38 & 0.130 & 9.025 & 0.608 & 0.995 & 11.635 & 0.355 & 0.821 & 5.940 & 19.240 & 16.582 \\
\hline WS30 & & 3.931 & 3.21 & 0.134 & 7.135 & 0.532 & 0.990 & 10.251 & 0.654 & 0.832 & 5.335 & 18.279 & 15.427 \\
\hline Average & & 4.549 & 3.65 & 0.130 & - & - & 0.987 & 11.927 & 1.016 & 0.814 & 5.329 & 19.391 & 17.615 \\
\hline WS31 & \multirow{5}{*}{$400^{\circ} \mathrm{C}$} & 3.584 & 2.56 & 0.136 & 3.934 & 0.307 & 0.999 & 11.737 & 1.033 & 0.921 & 6.937 & 14.557 & 12.391 \\
\hline WS32 & & 3.039 & 1.42 & 0.126 & 21.138 & 0.828 & 0.992 & 9.300 & 0.226 & 0.904 & 5.614 & 8.084 & 6.331 \\
\hline WS33 & & 3.228 & 2.12 & 0.114 & 2.100 & 0.224 & 0.995 & 8.533 & 1.575 & 0.842 & 5.819 & 7.348 & 6.419 \\
\hline WS34 & & 4.476 & 1.71 & 0.111 & 4.208 & 0.322 & 0.929 & 13.388 & 0.986 & 0.985 & 5.940 & 12.035 & 8.463 \\
\hline WS35 & & - & - & - & - & - & - & - & - & - & - & - & - \\
\hline Average & & 3.582 & 1.95 & 0.122 & - & - & 0.979 & 10.740 & 0.955 & 0.913 & 6.078 & 10.506 & 8.401 \\
\hline
\end{tabular}


TABle 1: Continued.

\begin{tabular}{lccccccccccccc}
\hline Specimen Temperature & $\begin{array}{c}P_{h \max } \\
(\mathrm{kN})\end{array}$ & $E(\mathrm{GPa})$ & $a_{c}(\mathrm{~mm})$ & $\beta / m$ & $\lambda / n$ & $R^{2}$ & $W_{1}$ & $W_{2}$ & $\mathrm{COD}_{c}(\mathrm{~mm})$ & $\begin{array}{c}\mathrm{COD}_{1}(\mathrm{~mm}) \\
(\mathrm{kN} / \mathrm{mm})\end{array}$ & $\begin{array}{c}K_{0} \\
(\mathrm{kN} / \mathrm{mm})\end{array}$ \\
\hline WS36 & & 3.336 & 1.41 & 0.125 & 5.280 & 0.299 & 0.977 & 13.124 & 1.553 & 1.224 & 5.625 & 8.037 & 6.289 \\
WS37 & & - & - & - & - & - & - & - & - & - & - & - & - \\
WS38 & $450^{\circ} \mathrm{C}$ & 3.118 & 1.46 & 0.123 & 10.235 & 0.543 & 0.981 & 10.601 & 0.978 & 1.057 & 5.672 & 8.291 & 6.216 \\
WS39 & & 3.056 & 1.34 & 0.127 & 2.518 & 0.137 & 0.995 & 11.955 & 3.960 & 1.281 & 6.784 & 7.611 & 6.099 \\
WS40 & & 2.935 & 1.58 & 0.137 & 4.328 & 0.226 & 0.998 & 13.896 & 2.395 & 1.394 & 6.000 & 8.988 & 6.900 \\
\hline Average & & 3.111 & 1.45 & 0.128 & - & - & 0.988 & 12.394 & 1.663 & 1.239 & 6.020 & 8.232 & 6.376 \\
\hline WS41 & & - & - & - & - & - & - & - & - & - & - & - & - \\
WS42 & & 2.153 & 1.76 & 0.146 & 3.056 & 0.245 & 0.976 & 7.762 & 3.054 & 1.284 & 5.153 & 7.251 & 7.506 \\
WS43 & $500^{\circ} \mathrm{C}$ & 2.857 & 1.09 & 0.119 & 3.648 & 0.306 & 0.979 & 10.092 & 1.342 & 1.174 & 6.533 & 6.179 & 5.069 \\
WS44 & & 1.929 & 0.75 & 0.109 & 2.234 & 0.153 & 0.968 & 8.758 & 4.119 & 1.225 & 6.591 & 4.243 & 3.651 \\
WS45 & & 1.838 & 1.48 & 0.147 & 2.300 & 0.186 & 0.996 & 7.826 & 3.012 & 1.354 & 6.225 & 6.078 & 6.591 \\
\hline Average & & 2.194 & 1.27 & 0.130 & - & - & 0.977 & 8.002 & 2.494 & 1.259 & 6.125 & 5.938 & 5.704 \\
\hline WS46 & & 1.129 & 0.47 & 0.130 & 2.102 & 0.278 & 0.931 & 4.197 & 1.280 & 1.482 & 7.000 & 2.656 & 2.094 \\
WS47 & & 1.474 & 0.48 & 0.128 & 3.018 & 0.238 & 0.954 & 7.245 & 2.236 & 1.784 & 10.000 & 2.718 & 2.233 \\
WS48 & $600^{\circ} \mathrm{C}$ & 1.649 & 1.14 & 0.152 & 1.992 & 0.132 & 0.979 & 8.390 & 4.551 & 1.908 & 7.100 & 3.909 & 2.858 \\
WS49 & & 1.138 & 0.38 & 0.131 & 1.183 & 0.120 & 0.971 & 5.018 & 2.950 & 1.865 & 10.000 & 1.165 & 1.761 \\
WS50 & & 1.243 & 0.38 & 0.124 & 2.507 & 0.285 & 0.943 & 5.273 & 1.280 & 1.644 & 8.000 & 1.174 & 1.727 \\
\hline Average & & 1.326 & 0.57 & 0.133 & - & - & 0.956 & 6.025 & 2.460 & 1.737 & 8.420 & 2.324 & 2.135 \\
\hline
\end{tabular}

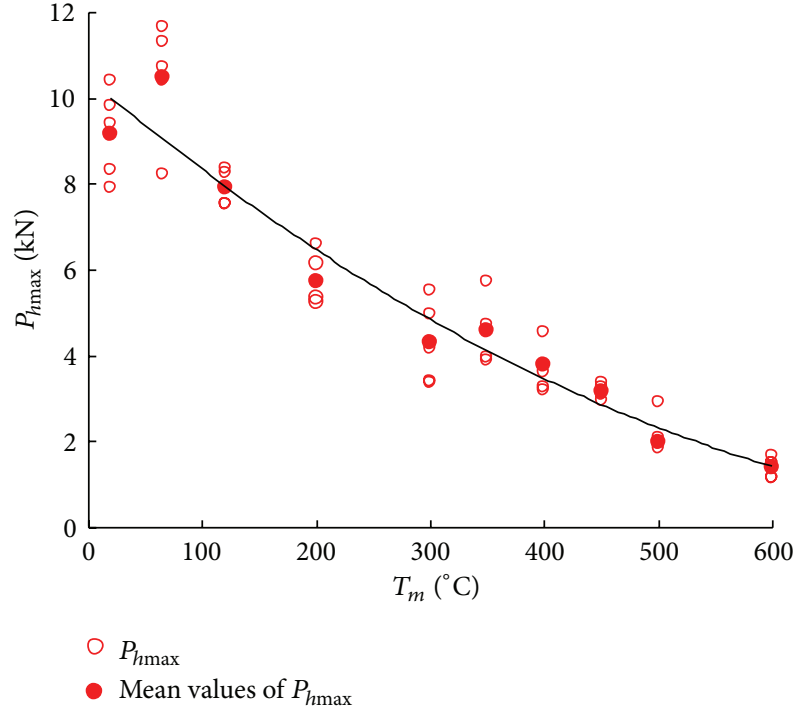

FIgURE 7: Variation tendency of $P_{h \max }$ with $T_{m}$.

of $K$ at any value of displacement is assumed to be linear with increased deformation [15].

$$
K=\frac{K_{0}\left(\mathrm{COD}_{1}-\mathrm{COD}\right)}{\left(\mathrm{COD}_{1}-\mathrm{COD}_{0}\right)}
$$

where $\mathrm{COD}_{1}=$ final deformation when the load $P$ approaches zero and $\mathrm{COD}_{0}=$ displacement before which the stiffness is still kept at $K_{0}$. At the origin of $P$-COD curve, the initial tangent stiffness is $K_{0}$. The stiffness becomes degraded beyond the origin point; hence $\mathrm{COD}_{0}$ is presumed to be zero. It is clear from (10) that $K=K_{0}$ when $\mathrm{COD}=0$ and

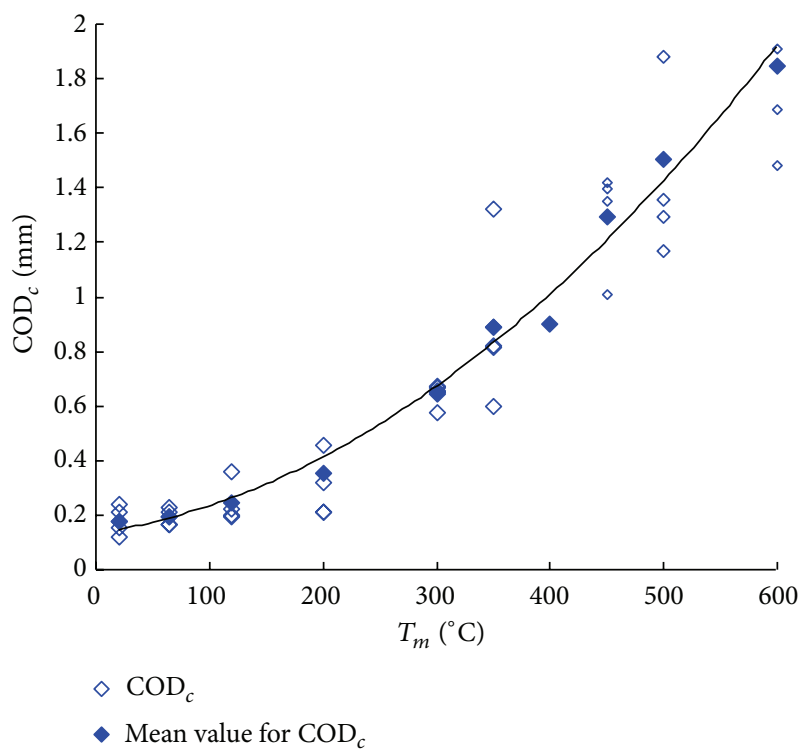

Figure 8: Variation tendency of $\mathrm{COD}_{c}$ with $T_{m}$.

$K=0$ when $=\mathrm{COD}_{1}$, and $K$ is assumed to be a linear function with respect to the displacement. With the crack opening displacement $\mathrm{COD}=\mathrm{COD}_{c}$, the stiffness $K_{c}$ at this point could approximately be obtained through (10). Note that $P$-COD is a general term for load-displacement; in our case, the load is the horizontal force $P_{h}$ and its corresponding displacement is the COD. Therefore, with $K_{0}, \mathrm{COD}_{1}$, and $\mathrm{COD}_{c}$, the approximate degraded stiffness $K_{c}$ can be gained from (10) and the result is shown in Table 1. Figure 11 shows that the values of stiffness $K_{c}$ decrease monotonously with temperature due to the thermal damage induced by high temperatures. 
TABLE 2: Fracture energies for crack propagation.

\begin{tabular}{|c|c|c|c|c|c|c|c|c|c|c|c|c|}
\hline \multicolumn{2}{|c|}{ Specimen Temperature } & \multirow{2}{*}{$\frac{W_{0}(\mathrm{Nm})}{5.620}$} & \multirow{2}{*}{$A_{\text {lig }}\left(\mathrm{m}^{2}\right)$} & \multirow{2}{*}{$\begin{array}{c}\begin{array}{c}G_{\mathrm{F}} \\
\left(\mathrm{Nm}^{-1}\right)\end{array} \\
234.147\end{array}$} & \multirow{2}{*}{$\begin{array}{c}\begin{array}{c}W_{\text {OIMA }} \\
(\mathrm{Nm})\end{array} \\
1.217\end{array}$} & \multirow{2}{*}{$\begin{array}{c}\begin{array}{c}W_{\text {AIMA }} \\
(\mathrm{Nm})\end{array} \\
0.407\end{array}$} & \multirow{2}{*}{$\begin{array}{c}\begin{array}{c}W_{\mathrm{FS}} \\
(\mathrm{Nm})\end{array} \\
0.810\end{array}$} & \multirow{2}{*}{$\begin{array}{c}A_{\mathrm{FS}} \\
\left(\mathrm{m}^{2}\right)\end{array}$} & \multirow{2}{*}{$\begin{array}{c}\begin{array}{c}G_{\mathrm{FS}} \\
\left(\mathrm{Nm}^{-1}\right)\end{array} \\
152.502\end{array}$} & \multirow{2}{*}{$\begin{array}{l}\begin{array}{l}W_{\mathrm{FU}} \\
(\mathrm{Nm})\end{array} \\
4.809\end{array}$} & \multirow{2}{*}{$\begin{array}{l}A_{\mathrm{FU}} \\
\left(\mathrm{m}^{2}\right)\end{array}$} & \multirow{2}{*}{$\frac{G_{\mathrm{FU}}\left(\mathrm{Nm}^{-1}\right)}{257.361}$} \\
\hline WS1 & & & & & & & & & & & & \\
\hline WS2 & \multirow{4}{*}{$20^{\circ} \mathrm{C}$} & 11.608 & \multirow{4}{*}{0.024} & 483.664 & 1.575 & 0.388 & 1.187 & 0.003 & 350.795 & 10.421 & 0.021 & 504.972 \\
\hline WS3 & & 10.517 & & 438.217 & 2.124 & 0.470 & 1.654 & 0.007 & 242.557 & 8.863 & 0.017 & 515.877 \\
\hline WS4 & & 5.265 & & 219.394 & 0.994 & 0.314 & 0.680 & 0.006 & 107.537 & 4.586 & 0.018 & 259.384 \\
\hline WS5 & & 7.705 & & 321.055 & 1.693 & 0.525 & 1.169 & 0.005 & 212.824 & 6.536 & 0.019 & 353.175 \\
\hline Average & & 8.143 & & 339.295 & 1.521 & 0.421 & 1.100 & 0.005 & 213.243 & 7.043 & 0.019 & 378.154 \\
\hline WS6 & \multirow{5}{*}{$65^{\circ} \mathrm{C}$} & 7.666 & \multirow{5}{*}{0.024} & 425.907 & 1.791 & 0.535 & 1.255 & 0.007 & 281.835 & 6.411 & 0.017 & 480.239 \\
\hline WS7 & & 8.687 & & 482.619 & 1.076 & 0.241 & 0.835 & 0.010 & 113.926 & 7.852 & 0.014 & 768.132 \\
\hline WS8 & & 8.779 & & 487.745 & 1.475 & 0.509 & 0.966 & 0.007 & 208.612 & 7.813 & 0.017 & 602.385 \\
\hline WS9 & & 8.649 & & 480.507 & 1.027 & 0.440 & 0.587 & 0.008 & 118.113 & 8.062 & 0.016 & 656.640 \\
\hline WS10 & & 9.402 & & 522.360 & 1.419 & 0.733 & 0.686 & 0.005 & 210.596 & 8.716 & 0.019 & 614.693 \\
\hline Average & & 8.637 & & 479.828 & 1.357 & 0.492 & 0.866 & 0.007 & 186.616 & 7.771 & 0.017 & 624.418 \\
\hline WS11 & \multirow{5}{*}{$120^{\circ} \mathrm{C}$} & 7.137 & \multirow{5}{*}{0.024} & 396.516 & 1.335 & 0.588 & 0.746 & 0.003 & 251.423 & 6.391 & 0.021 & 416.985 \\
\hline WS12 & & 9.321 & & 517.822 & 1.475 & 0.511 & 0.964 & 0.005 & 178.684 & 8.357 & 0.019 & 616.201 \\
\hline WS13 & & 11.785 & & 654.732 & 2.079 & 0.560 & 1.520 & 0.008 & 193.937 & 10.266 & 0.016 & 878.097 \\
\hline WS14 & & 6.218 & & 345.463 & 1.044 & 0.312 & 0.732 & 0.007 & 98.944 & 5.486 & 0.017 & 455.357 \\
\hline WS15 & & - & & - & - & - & - & - & - & - & - & - \\
\hline Average & & 8.615 & & 478.633 & 1.483 & 0.493 & 0.991 & 0.006 & 180.747 & 7.625 & 0.018 & 591.660 \\
\hline WS16 & \multirow{5}{*}{$200^{\circ} \mathrm{C}$} & - & \multirow{5}{*}{0.024} & - & - & - & - & - & - & - & - & - \\
\hline WS17 & & 6.780 & & 282.509 & 1.522 & 0.345 & 1.176 & 0.009 & 123.021 & 5.604 & 0.015 & 385.812 \\
\hline WS18 & & 5.163 & & 215.135 & 1.556 & 0.525 & 1.031 & 0.007 & 146.955 & 4.132 & 0.017 & 243.300 \\
\hline WS19 & & 5.662 & & 235.913 & 1.252 & 0.270 & 0.982 & 0.009 & 104.764 & 4.680 & 0.015 & 320.014 \\
\hline WS20 & & 8.854 & & 368.937 & 1.828 & 0.365 & 1.463 & 0.010 & 145.364 & 7.391 & 0.014 & 530.467 \\
\hline Average & & 6.615 & & 275.624 & 1.540 & 0.376 & 1.163 & 0.009 & 130.026 & 5.452 & 0.015 & 369.898 \\
\hline WS21 & \multirow{5}{*}{$300^{\circ} \mathrm{C}$} & 10.510 & & 437.920 & 2.005 & 0.439 & 1.566 & 0.008 & 188.640 & 8.944 & 0.016 & 568.895 \\
\hline WS22 & & 14.675 & & 611.467 & 3.546 & 0.820 & 2.726 & 0.007 & 364.621 & 11.949 & 0.017 & 723.160 \\
\hline WS23 & & 8.202 & 0.024 & 341.770 & 2.048 & 0.579 & 1.469 & 0.007 & 220.394 & 6.733 & 0.017 & 388.453 \\
\hline WS24 & & 13.539 & & 564.120 & 3.065 & 1.081 & 1.984 & 0.005 & 404.514 & 11.555 & 0.019 & 605.107 \\
\hline WS25 & & 13.200 & & 549.990 & 2.552 & 0.389 & 2.163 & 0.011 & 190.295 & 11.037 & 0.013 & 870.055 \\
\hline Average & & 12.025 & & 501.053 & 2.643 & 0.662 & 1.982 & 0.008 & 273.693 & 10.044 & 0.016 & 631.134 \\
\hline WS26 & & 13.765 & & 573.540 & 2.689 & 0.511 & 2.179 & 0.010 & 211.652 & 11.586 & 0.014 & 845.346 \\
\hline WS27 & & 15.639 & & 651.638 & 2.589 & 0.703 & 1.887 & 0.009 & 207.566 & 13.753 & 0.015 & 922.314 \\
\hline WS28 & $350 \mathrm{C}$ & 12.420 & 0.024 & 517.489 & 3.827 & 0.919 & 2.908 & 0.010 & 317.145 & 9.512 & 0.014 & 664.527 \\
\hline WS29 & & 11.990 & & 499.602 & 2.900 & 0.611 & 2.289 & 0.010 & 228.349 & 9.701 & 0.014 & 694.230 \\
\hline WS30 & & 10.905 & & 454.375 & 2.796 & 0.475 & 2.320 & 0.011 & 216.312 & 8.585 & 0.013 & 646.739 \\
\hline Average & & 12.944 & & 539.329 & 2.960 & 0.644 & 2.317 & 0.010 & 236.205 & 10.627 & 0.014 & 754.631 \\
\hline WS31 & & 12.770 & & 532.090 & 2.240 & 0.484 & 1.756 & 0.011 & 156.074 & 11.014 & 0.013 & 860.665 \\
\hline WS32 & & 9.526 & & 396.932 & 2.678 & 0.656 & 2.022 & 0.009 & 207.133 & 7.504 & 0.015 & 516.314 \\
\hline WS33 & $400^{\circ} \mathrm{C}$ & 10.109 & 0.024 & 421.188 & 2.411 & 0.760 & 1.651 & 0.007 & 242.302 & 8.457 & 0.017 & 491.692 \\
\hline WS34 & & 14.374 & & 598.926 & 3.638 & 0.918 & 2.720 & 0.006 & 401.879 & 11.654 & 0.018 & 668.062 \\
\hline WS35 & & - & & - & - & - & - & - & - & - & - & - \\
\hline Average & & 11.695 & & 487.284 & 2.742 & 0.705 & 2.037 & 0.008 & 251.847 & 9.658 & 0.016 & 634.184 \\
\hline
\end{tabular}


TABLE 2: Continued.

\begin{tabular}{|c|c|c|c|c|c|c|c|c|c|c|c|c|}
\hline Specimen & Temperature & $W_{0}(\mathrm{Nm})$ & $A_{\text {lig }}\left(\mathrm{m}^{2}\right)$ & $\begin{array}{c}G_{\mathrm{F}} \\
\left(\mathrm{Nm}^{-1}\right)\end{array}$ & $\begin{array}{c}W_{\text {OIMA }} \\
(\mathrm{Nm})\end{array}$ & $\begin{array}{c}W_{\text {AIMA }} \\
(\mathrm{Nm})\end{array}$ & $\begin{array}{c}W_{\mathrm{FS}} \\
(\mathrm{Nm})\end{array}$ & $\begin{array}{l}A_{\mathrm{FS}} \\
\left(\mathrm{m}^{2}\right)\end{array}$ & $\begin{array}{c}G_{\mathrm{FS}} \\
\left(\mathrm{Nm}^{-1}\right)\end{array}$ & $\begin{array}{l}W_{\mathrm{FU}} \\
(\mathrm{Nm})\end{array}$ & $\begin{array}{l}A_{\mathrm{FU}} \\
\left(\mathrm{m}^{2}\right)\end{array}$ & $G_{\mathrm{FU}}\left(\mathrm{Nm}^{-1}\right)$ \\
\hline WS36 & \multirow{5}{*}{$450^{\circ} \mathrm{C}$} & 14.677 & \multirow{5}{*}{0.024} & 611.530 & 3.255 & 0.779 & 2.477 & 0.009 & 277.088 & 12.200 & 0.015 & 809.983 \\
\hline WS37 & & - & & - & - & - & - & - & - & - & - & - \\
\hline WS38 & & 11.579 & & 482.451 & 3.284 & 0.669 & 2.615 & 0.009 & 303.750 & 8.964 & 0.015 & 582.382 \\
\hline WS39 & & 15.914 & & 663.097 & 3.281 & 0.704 & 2.578 & 0.009 & 272.015 & 13.337 & 0.015 & 918.284 \\
\hline WS40 & & 16.291 & & 678.790 & 3.847 & 0.532 & 3.315 & 0.011 & 292.743 & 12.976 & 0.013 & 1023.630 \\
\hline Average & & 14.057 & & 608.967 & 3.417 & 0.671 & 2.746 & 0.010 & 286.399 & 11.869 & 0.014 & 833.570 \\
\hline WS41 & \multirow{5}{*}{$500^{\circ} \mathrm{C}$} & - & \multirow{5}{*}{0.024} & - & - & - & - & - & - & - & - & - \\
\hline WS42 & & 10.816 & & 450.668 & 2.080 & 0.355 & 1.725 & 0.013 & 138.244 & 9.091 & 0.011 & 831.501 \\
\hline WS43 & & 11.434 & & 476.413 & 2.890 & 0.743 & 2.146 & 0.008 & 272.496 & 9.288 & 0.016 & 576.031 \\
\hline WS44 & & 12.877 & & 536.544 & 1.495 & 0.475 & 1.021 & 0.006 & 170.514 & 11.856 & 0.018 & 652.188 \\
\hline WS45 & & 10.838 & & 451.571 & 2.720 & 0.308 & 2.412 & 0.013 & 186.562 & 8.426 & 0.011 & 785.892 \\
\hline Average & & 10.496 & & 478.799 & 2.296 & 0.470 & 1.826 & 0.010 & 191.954 & 9.665 & 0.014 & 711.403 \\
\hline WS46 & \multirow{5}{*}{$600^{\circ} \mathrm{C}$} & 5.477 & \multirow{5}{*}{0.024} & 228.226 & 1.404 & 0.287 & 1.117 & 0.010 & 110.974 & 4.361 & 0.014 & 312.890 \\
\hline WS47 & & 9.481 & & 395.057 & 2.526 & 0.460 & 2.066 & 0.010 & 213.423 & 7.415 & 0.014 & 517.849 \\
\hline WS48 & & 12.941 & & 539.225 & 2.621 & 0.389 & 2.232 & 0.014 & 155.808 & 10.709 & 0.010 & 1107.140 \\
\hline WS49 & & 7.968 & & 331.988 & 1.514 & 0.635 & 0.879 & 0.010 & 115.238 & 7.088 & 0.014 & 491.494 \\
\hline WS50 & & 6.554 & & 273.074 & 1.749 & 0.773 & 0.976 & 0.009 & 151.878 & 5.578 & 0.015 & 342.831 \\
\hline Average & & 8.484 & & 353.514 & 1.963 & 0.509 & 1.454 & 0.011 & 149.464 & 7.030 & 0.013 & 632.922 \\
\hline
\end{tabular}

The stable fracture energy $G_{\mathrm{FS}}$ and unstable fracture energy $G_{\mathrm{FU}}$ can be derived by following (11) (13). The specific values of $G_{\mathrm{FS}}$ and $G_{\mathrm{FU}}$ are compiled in Table 2:

$$
\begin{gathered}
G_{\mathrm{FS}}=\frac{W_{\mathrm{FS}}}{A_{\mathrm{S}}}=\frac{W_{\mathrm{OAMO}}}{A_{\mathrm{S}}}=\frac{W_{\mathrm{OIMO}}-W_{\mathrm{AIMA}}}{A_{\mathrm{S}}}, \\
G_{\mathrm{FU}}=\frac{W_{U}}{A_{U}}=\frac{W-W_{\mathrm{FS}}}{A_{U}}, \\
A_{\mathrm{S}}=B\left(a_{c}-a_{0}\right), \quad A_{U}=B\left(h-a_{c}\right), \\
W_{\mathrm{AIMA}}=\frac{0.5 P_{h \max }{ }^{2}}{K_{c}} .
\end{gathered}
$$

Figure 12 shows the variation of stable fracture energy $G_{\mathrm{FS}}$ with temperatures. Similar to the residual fracture energy $G_{F}$, it also keeps an increase-decrease tendency with temperatures. Temperatures less than $120^{\circ} \mathrm{C}$ appear not to induce much thermal damage to concrete, so the cracking resistance almost keeps constant. The values of stable fracture energy $G_{\mathrm{FS}}$ at these temperatures are $213 \mathrm{Nm}^{-1}, 186 \mathrm{Nm}^{-1}$, and $180 \mathrm{Nm}^{-1}$, respectively. The fracture surfaces tend to be more tortuous between $200^{\circ} \mathrm{C}$ and $450^{\circ} \mathrm{C}$ than those observed at lower temperatures (see Figure 4) and there exist several cracks competing to form the final fracture, so more energy was dissipated in these specimens. Additionally, the opening of microcracks on the surface and inside the specimens also dissipates energy (see Figure 3). Finally, higher heating temperatures would cause more micro cracks, dehydration, and decomposition and would degrade the resistance. After $450^{\circ} \mathrm{C}$, cracking resistance continuously decreases with $T_{m}$.
Table 2 shows that the unstable fracture $G_{\mathrm{FU}}$ also sustains an increase-decrease tendency with $T_{m}$, and its value is much larger than stable fracture energy. Two reasons for larger values of $G_{\mathrm{FU}}$ are provided [5]. First, energy consumption besides the main fracture zone takes places for the whole fracture process. During the unstable fracture process, the energy consumption for plasticity or other nonlinear deformation beyond the main FPZ would be much higher, especially for specimens subjected to high temperatures. The other possible reason lies in the calculation of true fracture area. It is known that the interface (transition zone) between cement and aggregate is the weak link in microstructure for normal concrete, and crack propagation would proceed in the path where the energy needs are least. So the true path of crack extension is tortuous and the higher the temperature is, the more tortuous the fracture surface is (see Figure 4), not straight as expected. The projected area is used in the calculation of fracturing surface $A_{\mathrm{S}}$ or $A_{\mathrm{U}}$, which underestimates the true fracture area. Since the crack experiences much longer distance for the unstable extension, which leads to a greater underestimation of the calculation of the newly fractured area $A_{\mathrm{U}}$, the calculated $G_{\mathrm{FU}}$ is overestimated.

Moreover, in view of (11) and (12), another expression for the fracture energy $G_{\mathrm{F}}$ with respect to $G_{\mathrm{FS}}$ and $G_{\mathrm{FU}}$ can be followed:

$$
G_{\mathrm{F}}=\frac{W}{A}=\frac{G_{\mathrm{FS}} A_{\mathrm{S}}+G_{\mathrm{FU}} A_{\mathrm{U}}}{A}=G_{\mathrm{FS}} \cdot \frac{A_{\mathrm{S}}}{A}+G_{\mathrm{FU}} \cdot \frac{A_{\mathrm{U}}}{A} .
$$

Since $A_{\mathrm{S}}+A_{\mathrm{U}}=A$, the fracture energy $G_{\mathrm{F}}$ is the weighed average of $G_{\mathrm{FS}}$ and $G_{\mathrm{FU}}$. However, for engineering application, the stable crack propagation is considered to be more 


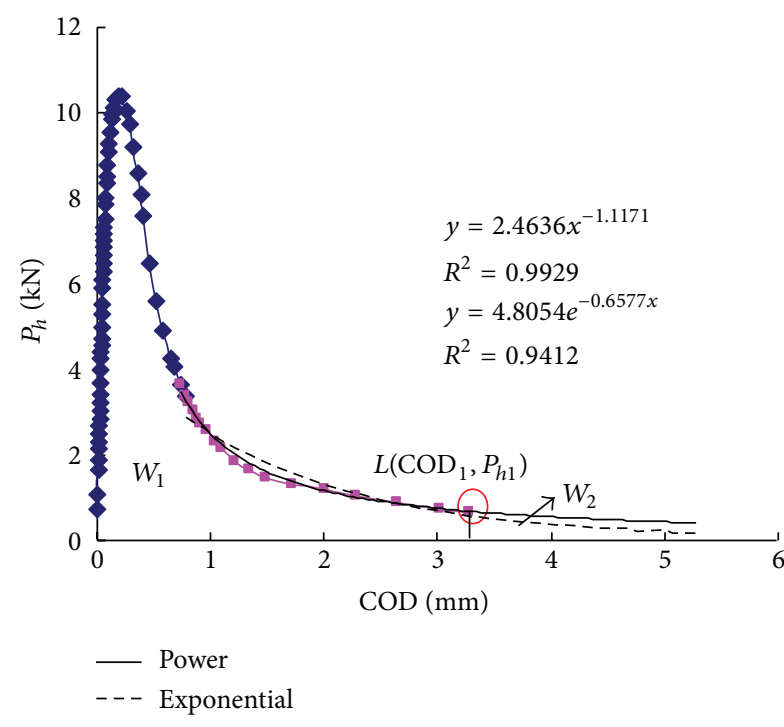

(a) Curve fitting for specimen of ambient temperature

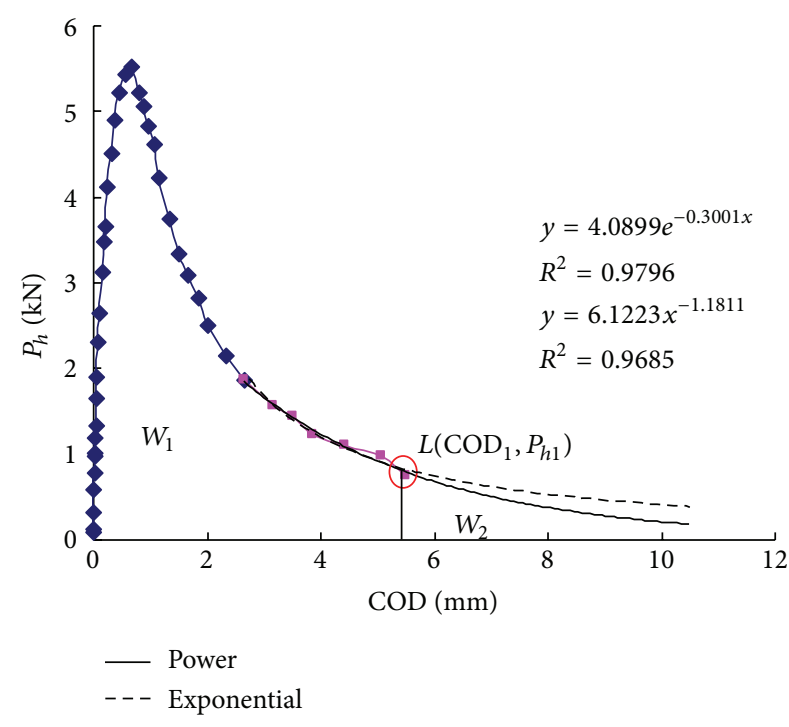

(b) Curve fitting for specimen of $200^{\circ} \mathrm{C}$

Figure 9: P-CMOD tail curve fitting of specimens.

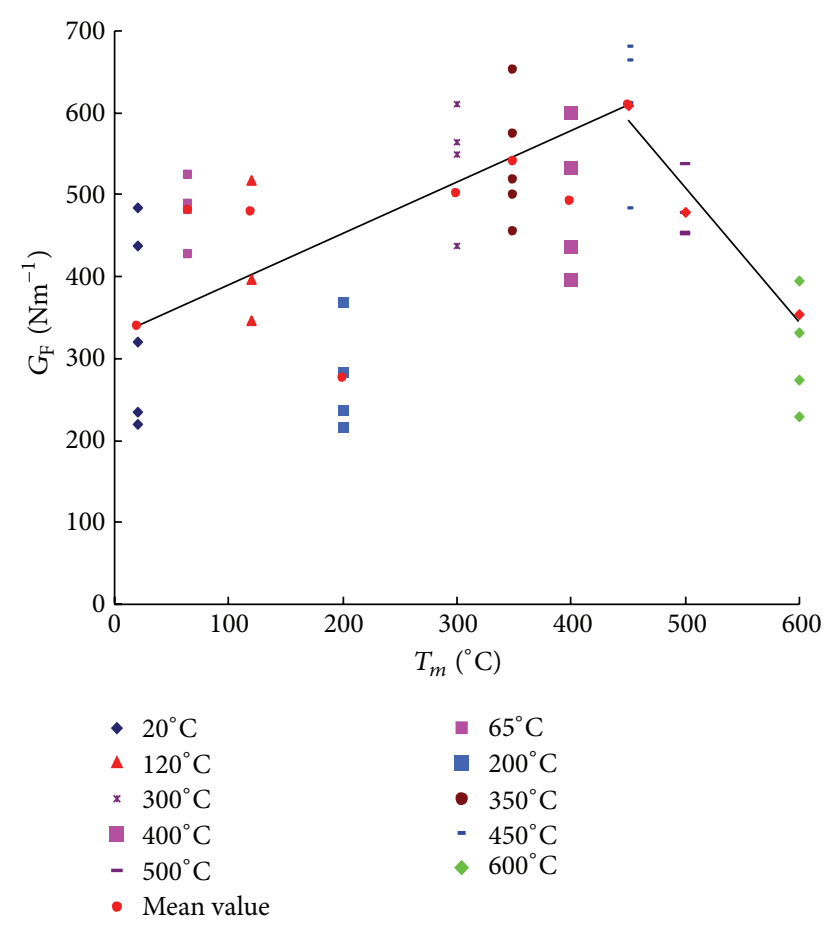

FIgURE 10: Residual fracture energy with $T_{m}$.

important, because when the load exceeds the maximum value the whole structure would be in an unstable situation. Hence from Figures 7 and 9, it is concluded that the fracture property of postfire concrete sustains an increase-decrease tendency to $600^{\circ} \mathrm{C}$, with a turning point at $450^{\circ} \mathrm{C}$.

Furthermore, as mentioned above, the fracture surfaces of $A, A_{\mathrm{S}}, A_{\mathrm{U}}$ are project areas, so $G_{\mathrm{F}}, G_{\mathrm{FS}}, G_{\mathrm{FU}}$ are nominal fracture energies. To avoid the violence of fracture surface, the variation tendency of stable fracture work $W_{\mathrm{FS}}$ is determined

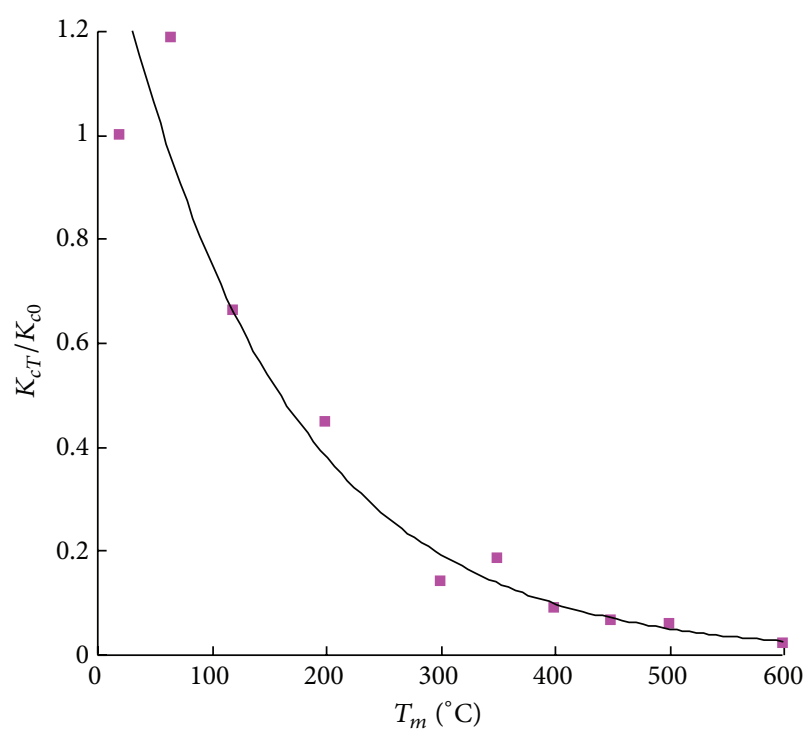

Figure 11: Stiffness $K_{c}$ with $T_{m}$.

(see Figure 10). Similarly, $W_{\mathrm{FS}}$ also keeps an increase-decrease tendency at the same turning temperature of $450^{\circ} \mathrm{C}$.

\section{Conclusions}

Energy consumption during an entire crack propagation period has been investigated, including the fracture energy $G_{\mathrm{F}}$, stable fracture energy $G_{\mathrm{FS}}$, unstable fracture energy $G_{\mathrm{FU}}$, and stable fracture work $W_{\mathrm{FS}}$. The conclusions are as follows.

(1) Wedge-splitting tests of ten temperatures levels varying from room temperature to $600^{\circ} \mathrm{C}$ and the specimen size of $230 \mathrm{~mm} \times 200 \mathrm{~mm} \times 200 \mathrm{~mm}$ with initialnotch depth ratios 0.4 have been presented. Complete $P$-COD curves and the curve tails are obtained using 


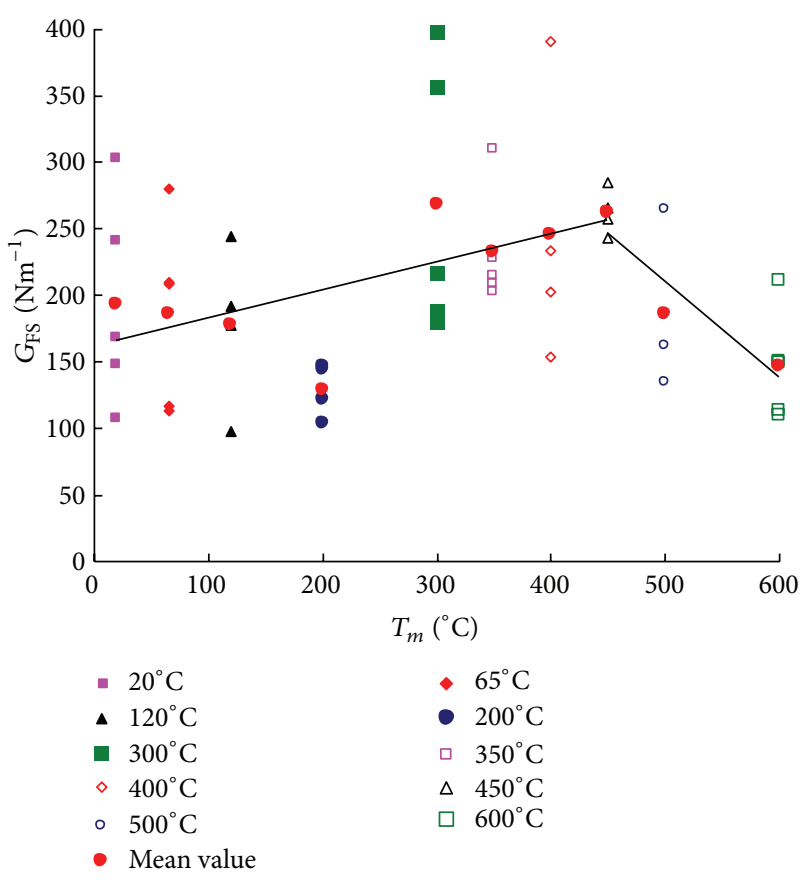

Figure 12: Stable fracture energy with $T_{m}$.

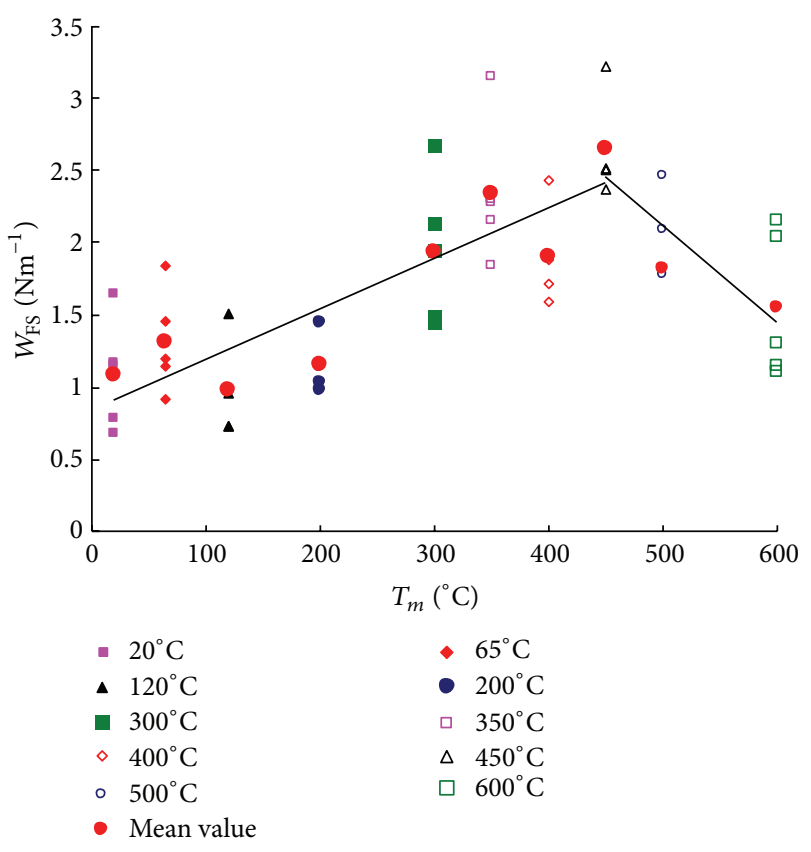

FIGURE 13: Stable fracture work with $T_{m}$.

exponential and power functions. For specimens subject to no more than $120^{\circ} \mathrm{C}$, the power function is more accurate; for higher temperatures, exponential function is more suitable.

(2) Three fracture energy quantities corresponding to different aspects of fracture are proposed. The fracture energy $G_{\mathrm{F}}$ in a general case only represents the average energy dissipation for an entire crack propagation process. $G_{\mathrm{FS}}$, the stable fracture energy, denotes the average energy absorption during crack stable propagation, and $G_{\mathrm{FU}}$ is used to characterize the average energy consumption for crack unstable propagation and a higher value of $G_{\mathrm{FU}}$ than $G_{\mathrm{FS}}$ is observed. $G_{\mathrm{F}}$ is actually the weighed average of $G_{\mathrm{FS}}$ and $G_{\mathrm{FU}}$.

(3) However, for engineering applications, the stable crack propagation is considered to be more important. From the wedge-splitting tests of different temperatures, it is concluded that $G_{\mathrm{F}}, G_{\mathrm{FS}}$ sustain an increase-decrease tendency to $600^{\circ} \mathrm{C}$, with a turning point at $450^{\circ} \mathrm{C}$. Furthermore, the variation of stable fracture work $W_{\mathrm{FS}}$ is determined and shares the same tendency with $G_{\mathrm{F}}$ and $G_{\mathrm{FS}}$ (Figure 13). All these three parameters mean that the fracture property of postfire concrete sustains an increase-decrease tendency.

\section{Acknowledgments}

The State Key Laboratory of Disaster Reduction in Civil Engineering (SLDRCE09-D-02) and Young Scientist Project of Natural Science Foundation of China (NSFC) have supported this research.

\section{References}

[1] A. Hillerborg, "The theoretical basis of a method to determine the fracture energy $G_{\mathrm{F}}$ of concrete," Materials and Structures, vol. 18, no. 4, pp. 291-296, 1985.

[2] RILEM-Draft-Recommendation (50-FCM) (RILEM), "Determination of the fracture energy of mortar and concrete by means of three-point bend tests on notched beams," RILEM Materials and Structures, vol. 18, no. 4, pp. 285-290, 1985.

[3] ASTM International Standard E399-06, "Standard test method for linear-elastic method plane-strain fracture toughness $K_{\mathrm{IC}}$ of Metallic Materials," 2006.

[4] E. Brühwiler and F. H. Wittmann, "The wedge splitting test, a new method of performing stable fracture mechanics tests," Engineering Fracture Mechanics, vol. 35, no. 1-3, pp. 117-125, 1990.

[5] S. Xu and H. W. Reinhardt, "Determination of double-K criterion for crack propagation in quasi-brittle fracture, Part I: experimental investigation of crack propagation," International Journal of Fracture, vol. 98, no. 2, pp. 111-149, 1999.

[6] S. Xu, Y. Zhao, and Z. Wu, "Study on the average fracture energy for crack propagation in concrete," Journal of Materials in Civil Engineering, vol. 18, no. 6, pp. 817-824, 2006.

[7] Z. P. Bazand and P. C. Prat, "Effect of temperatures and humidity on fracture energy of concrete," ACI Materials Journal, vol. 85, no. 4, pp. 262-271, 1988.

[8] G. Baker, "The effect of exposure to elevated temperatures on the fracture energy of plain concrete," Materials and Structures, vol. 29, no. 190, pp. 383-388, 1996.

[9] B. Zhang, N. Bicanic, C. J. Pearce, and G. Balabanic, "Residual fracture properties of normal- and high-strength concrete subject to elevated temperatures," Magazine of Concrete Research, vol. 52, no. 2, pp. 123-136, 2000.

[10] C. V. Nielsen and N. Bićanić, "Residual fracture energy of highperformance and normal concrete subject to high temperatures," Materials and Structures, vol. 36, no. 262, pp. 515-521, 2003. 
[11] B. Zhang and N. Bicanic, "Fracture energy of high-performance concrete at high temperatures up to $450^{\circ} \mathrm{C}$ : the effects of heating temperatures and testing conditions (hot and cold)," Magazine of Concrete Research, vol. 58, no. 5, pp. 277-288, 2006.

[12] J. Yu, K. Yu, and Z. Lu, "Residual fracture properties of concrete subjected to elevated temperatures," Materials and Structures, vol. 45, no. 8, pp. 1155-1165, 2012.

[13] Y. H. Zhao, The analytical study on the energy in the fracture process of concrete [Ph.D. thesis], Dalian University of Technology, Dalian, China, 2002.

[14] S. Xu and H. W. Reinhardt, "Crack extension resistance and fracture properties of quasi-brittle softening materials like concrete based on the complete process of fracture," International Journal of Fracture, vol. 92, no. 1, pp. 71-99, 1998.

[15] R. K. Navalurkar, C. T. Hsu, S. K. Kim, and M. Wecharatana, "True fracture energy of concrete," ACI Materials Journal, vol. 96, no. 2, pp. 213-225, 1999. 

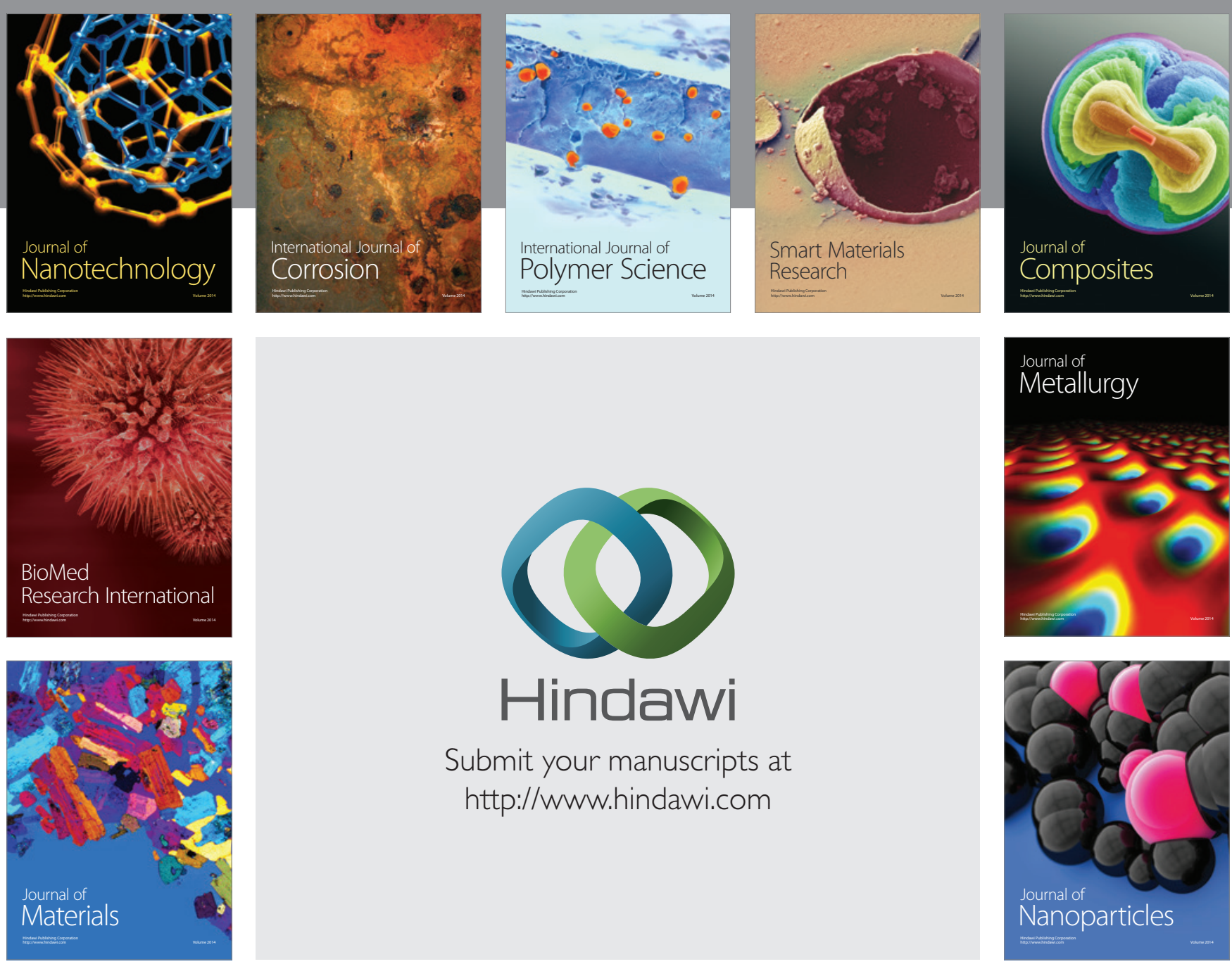

Submit your manuscripts at http://www.hindawi.com
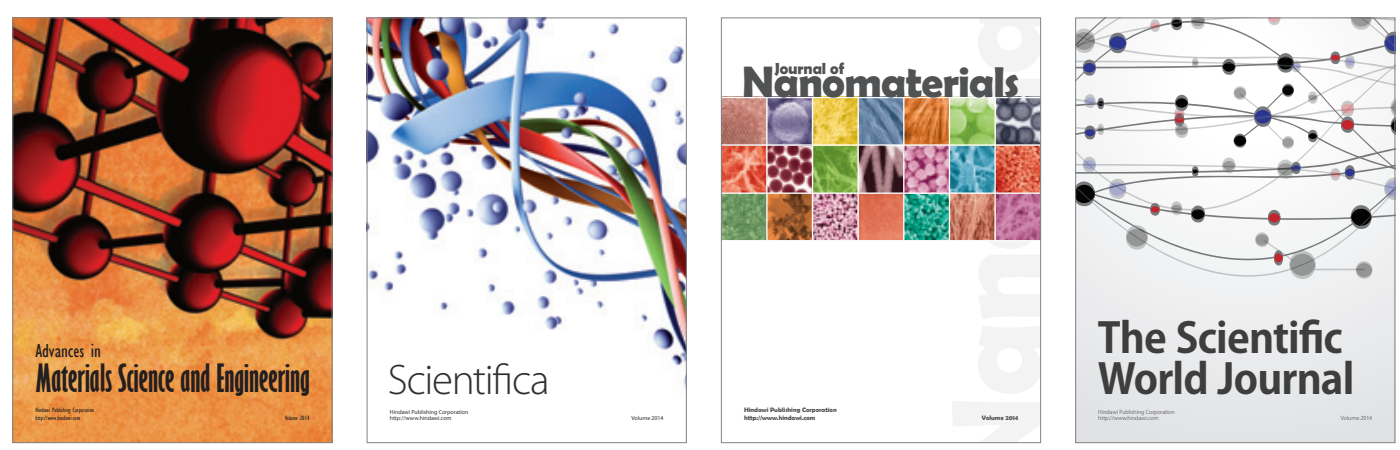

\section{The Scientific World Journal}
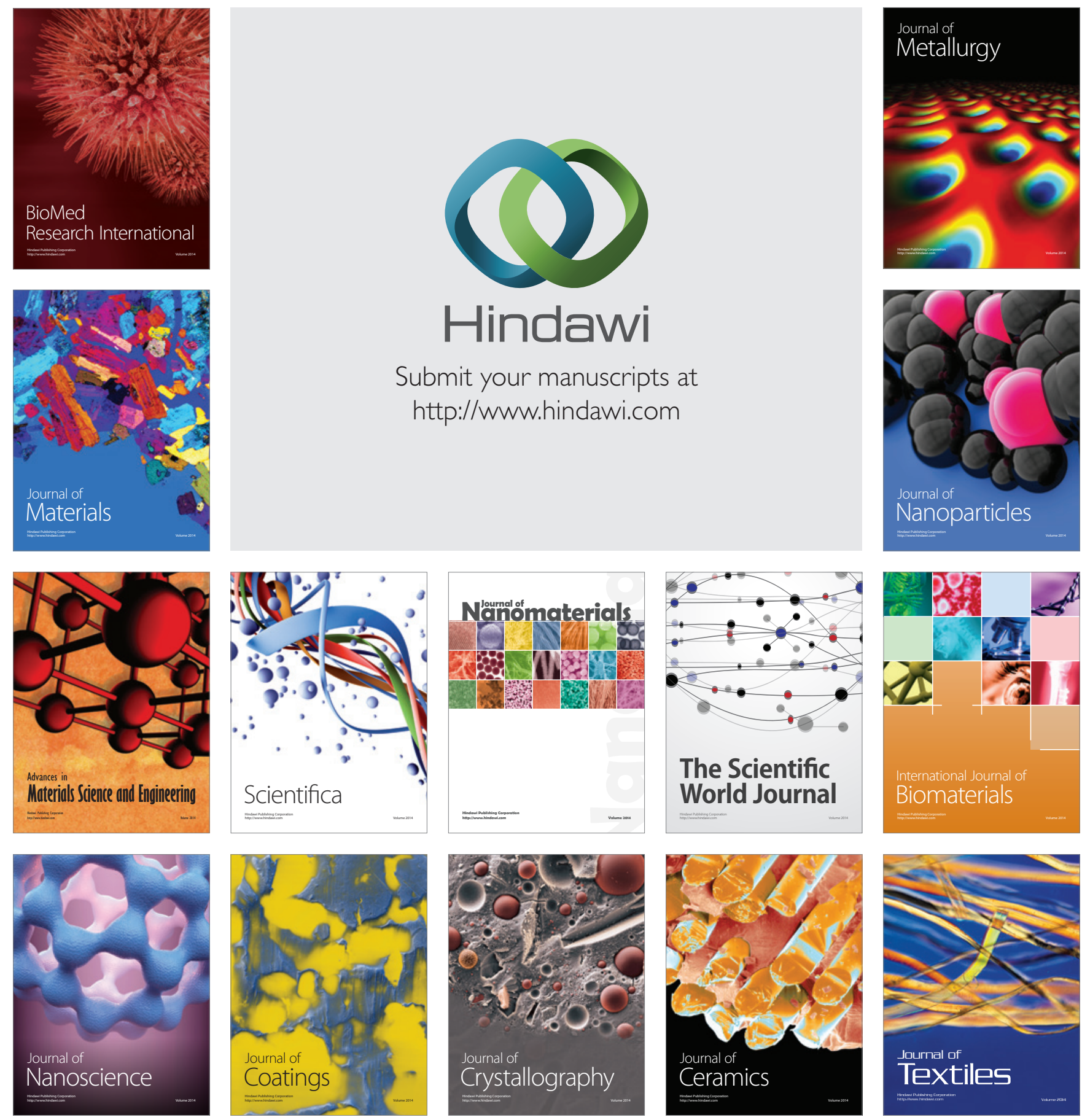